\title{
Past experiences with surprise medical bills drive issue knowledge, concern and attitudes toward federal policy intervention
}

\author{
Timothy Callaghan $^{1}$ (D), Simon F. Haeder ${ }^{2 \star}$ (D) and Steven Sylvester ${ }^{3}$ \\ ${ }^{1}$ Department of Health Policy and Management, School of Public Health, Texas A\&M University, 212 Adriance Lab Rd., \\ 1266 TAMU, College Station, TX, USA, ${ }^{2}$ School of Public Policy, The Pennsylvania State University, 322 Pond Laboratory, \\ University Park, PA, USA and ${ }^{3}$ Department of History and Political Science, Utah Valley University, 800 West University \\ Parkway, Orem, UT, USA \\ ${ }^{*}$ Corresponding author. Email: sfh5482@psu.edu
}

(Received 19 August 2020; revised 13 August 2021; accepted 7 September 2021; first published online 21 October 2021)

\begin{abstract}
Scholars and journalists have devoted considerable attention to understanding the circumstances in which Americans receive surprise medical bills. Previous research on this issue has focused on the scope of the problem, including the conditions that are most likely to lead to surprise bills. However, the existing literature has almost exclusively relied on claims data, limiting our understanding of consumer experiences and attitudes toward policy changes to address surprise billing. Using a survey administered to a nationally representative sample of 4998 Americans, we analyze consumer experiences with surprise billing, knowledge of the issue, how concerned Americans are about receiving surprise bills and how past experiences influence policy preferences toward federal action on surprise billing. Our analysis demonstrates that knowledge and concern about surprise billing are the highest among the educated and those who have previously received a surprise bill. These factors also predict support for federal policy action, with high levels of support for federal policy action across the population, including among both liberals and conservatives. However, more detailed federal policy proposals receive significantly less support among Americans, suggesting that stand-alone policy action may not be viable. Our results show bipartisan support among American consumers for federal action on surprise billing in the abstract but no consistent views on specific policy proposals.
\end{abstract}

Keywords: Health policy; medical bills; public opinion; surprise billing

Over the last several years, scholars have devoted considerable attention to better understanding an increasingly common phenomenon in the U.S. health care system: surprise medical billing. Surprise medical bills are bills for medical services that patients unexpectedly receive for care that they reasonably thought would be covered by their insurance (Adler et al., 2017, 2019; Garmon and Chartock, 2017). In most circumstances, these bills occur when patients receive care outside of their health plan's contracted network of providers and hospitals (Adler et al., 2017). Importantly, these bills are often triggered when patients leave their insurer's network unknowingly or involuntarily due to the complex and convoluted nature of the U.S. medical system (Haeder et al., 2019b).

Surprise medical bills have also been covered prominently by the media. Some of the most outrageous bills have been featured in the Kaiser Health News 'Bill of the Month' reporting series, including a family's $\$ 142,938$ bill for their child’s snakebite (Rodriguez, 2019), a man’s $\$ 540,842$ 
bill for dialysis (Gold, 2019) and a parent's \$2659 bill to remove a toy shoe from their child's nostril (Hawryluk and O'Neill, 2019). The coronavirus pandemic has added additional importance to the issue. A recent analysis by the Kaiser Family Foundation's Health System Tracker estimated that one in five patients admitted to hospitals because of coronavirus disease 2019 (COVID-19) might face a surprise medical bill (Rae et al., 2020).

Although not all surprise bills reach outrageous proportions, media reporting and public outcries have pushed policymakers into action. Indeed, states were the first to answer the call by implementing policies to limit surprise bills, albeit varying significantly in the extent and quality of the protections provided (Hoadley et al., 2019b). However, states are inherently limited in their capacity to shield consumers from surprise bills by the confines of the Employee Retirement Income Security Act of 1974 (ERISA), which preempts their ability to regulate self-funded employer plans. Given these constraints at the state level, scholars and advocates have long called for a comprehensive solution that better protects all Americans via federal policy change (Adler et al., 2017; Bindman, 2018; Adler et al., 2019; Dekhne et al., 2019). Legislators from both sides of the aisle in Washington, D.C. have proposed policies to reduce the frequency of surprise bills and blunt their impact on Americans. However, even as several proposals to limit the impact of surprise bills on Americans began to emerge nationally, they were subject to fierce lobbying and advertising blitzes by insurers, hospitals, physicians and even private equity firms (Bluth and Huetteman, 2019). As a result, until recently, there has been more blustering than action, and none of the proposals passed even a single chamber of the U.S. Congress (Bindman, 2018; Bluth, 2019; Dekhne et al., 2019) until legislators were pushed into action by the COVID-19 pandemic (Hoadley et al., 2020b). Tellingly, even then, the protections had to 'hitch a ride' on an omnibus appropriation bill and could not pass muster on their own (Krutz, 2001). Concerns about the extent of the protections as well as enforcement of the new federal legislation remain.

Critically, despite significant media attention focused on these federal efforts and several recent studies revealing critical gaps in the American health insurance system, we still know very little about the broader public's knowledge of and experiences with surprise medical bills, and how these experiences shape American attitudes toward federal policy change. This is mainly because prior research relies almost exclusively on insurance data to study surprise billing instead of understanding the impact of these billing practices on American consumers more broadly (Chhabra et al., 2020a; Cooper et al., 2020). By definition, insurance claims data are limited to consumers who received care from a subset of carriers and, importantly, within a specified time frame. Unfortunately, it does not include the perspectives of the consumers themselves, which are vital to understanding how the public feels about the growing problem and which policy solutions they would like to see implemented to address the issue.

Recent opinion polling has made some progress in improving our understanding of public experiences, suggesting that surprise billing is common, that most Americans are concerned about the possibility of a surprise bill, and that the desire for federal policy change is widespread (Kirzinger et al., 2018; Families USA, 2019; Kirzinger et al., 2019). However, this study exclusively presents topline survey results and does not move beyond these aggregated findings to study the factors that influence public sentiment on the topic. We argue that more in-depth opinion-based research is needed to gage Americans' perceptions of surprise medical billing. Specifically, research is needed to analyze the correlates of public attitudes toward surprise billing and how past experiences with surprise bills shape subsequent attitudes toward policies designed to put an end to the practice. Our analysis does just that.

We proceed as follows: we begin by outlining the developments that have contributed to the emergence and growth in surprise billing in the United States, as well as the responses of policymakers to protect consumers. We then provide an overview of existing research on surprise billing and related public opinion. Next, relying on large-scale original survey research conducted prior to recent federal action, we explore American knowledge of the growing problem, who in the general public is most concerned about the possibility of future surprise medical bills, and, perhaps 
most importantly, the key drivers of support or opposition for various policy proposals discussed at the federal level. We conclude by highlighting the implications of our findings for the U.S. political system and by exploring possibilities for future action on the issue.

\section{The emergence and growth of surprise billing}

The emergence of surprise billing in the United States can be traced to an important transformation of private health insurance in the late 1970s and early 1980s: the shift in American insurance away from indemnity plans and toward managed care arrangements designed to reign in health care spending (Gabel et al., 2000; Gray 2006). Although indemnity plans impose few restrictions on consumers, managed care coverage arrangements rely heavily on establishing provider networks that give preferential access to a subset of providers while excluding all others (Haeder et al., 2015b). Over time, as these managed care approaches have failed to reduce health costs as intended, insurers have started to pursue various cost containment strategies aggressively. These strategies initially focused on medical underwriting and policy rescission (Reinhardt, 2019). When the Affordable Care Act eliminated these instruments, however, efforts shifted to focus on narrowing the composition and breadth of provider networks (Haeder et al., 2015a; Brown et al., 2016; Polsky et al., 2016; Jacobson et al., 2017; Feyman et al., 2019). Although this narrowing of provider networks was an effort to hold down costs, it has had an unintended consequence - increasing the probability that privately insured individuals will have a medical encounter not covered by their managed care insurance plan.

At the same time, vertical and horizontal mergers of health care providers have contributed to the growing surprise bill problem. In merging, providers have sought to establish local and regional dominance, which they can leverage in negotiations to maximize reimbursements and profits (Ho and Hamilton, 2000; Fulton, 2017; Rosenthal, 2017). Some providers have gone a step further and made surprise billing a mainstay of their business model, deliberately opting out of participating in any networks at all to maximize income (Cooper et al., 2019; Young et al., 2019). These strategies appear particularly common among practice groups run by private equity companies (Bluth and Huetteman, 2019; Cooper et al., 2019).

In short, surprise billing has emerged as a major policy issue in the United States because a large number of individuals rely on private health insurance to pay for their medical care and most private insurance arrangements today are based on a managed-care framework, as opposed to indemnity coverage. Managed care coverage relies on differentiating between in-network and out-of-network providers with corresponding cost differences strongly favoring in-network care. As managed care networks have shrunk in an attempt to reduce costs, the chances have increased that any given medical encounter could result in an unexpected out-of-network charge.

Yet, it takes two to tango, and medical providers, not just insurers, have played an important role in the growth of surprise billing as they have sought to exploit their market power to extract rents from insurance carriers. The problem has been further exacerbated by some providers like emergency room staffing firms deliberately embarking on business strategies that rely on nonparticipation in networks and maximizing profits through surprise billing (Cooper et al., 2019). Ultimately, consumers are left holding the bag. As the late health economist Uwe Reinhardt put it, 'It is hard to think of a more unfair financial arrangement between patients and the healthcare system, one in which the buy-side is virtually defenseless vis-à-vis the supply side, and it is hard to imagine that any other country would allow it' (Reinhardt, 2019).

\section{Policy action on surprise billing}

Given the growing prevalence of surprise billing and subsequent media attention to the issue, it is not surprising that policymakers in recent years have been called upon to take action. At the state level, efforts have emphasized reducing the incidence of balance billing - the practice in which 
patients are billed for the difference between the charges of out-of-network care and the amount paid by insurance plans (Lucia et al., 2017; Chhabra et al., 2020a). Overall, more than half of the states have taken action on the issue (Hoadley et al., 2019b). However, state efforts in this area have varied dramatically in terms of quality and scope. A recent report from The Commonwealth Fund indicates that while 29 states have taken action on balance billing, just 15 states have been rated as having a 'comprehensive approach' (Hoadley et al., 2020c). States that have enacted consumer protections vary widely from deep blue California to deep red Mississippi (Hoadley et al., 2019b). However, the regulatory reach of states is stunted by the Employee Retirement Income Security Act of 1974 (ERISA), which exempts almost 100 million Americans in self-insured plans from state insurance regulations (Haeder, 2014; Adler et al., 2017).

As mentioned above, Congress has not stood by idly, and a number of competing bills have emerged in both the U.S. House and Senate to address surprise billing. Even in the current era of deep partisan divisions, many of these bills have found bipartisan support (Hoadley et al., 2020a). However, opposition to changing current billing practices from those who benefit from the current system has been fierce. Federal efforts to confront surprise billing have been met with significant lobbying campaigns (Evers-Hillstrom, 2019), campaign donations for opponents of change (Pradhan, 2020) and advertising by stakeholders (Sanger-Katz et al., 2019). Disputes have mainly emerged over standards for payments and dispute resolution mechanisms acceptable to all parties (Hoadley et al., 2019a, 2020a, 2020b, 2020c).

At the time of our study, this interest group opposition had prevented any legislation from garnering enough votes to pass both chambers of Congress. Many observers were skeptical that any protections would be signed into law in a reasonable timeframe (Scott, 2020). Yet, the deadlock was broken when Congress passed federal surprise billing protections at the end of 2020, with protections set to take effect in 2022. Critically, however, the way passage was ultimately achieved is emblematic of the controversial nature of the issue: surprise billing protections had to be attached to the must-pass omnibus spending bill, H.R.133 Consolidated Appropriations Act, 2021, because they were not viable in the short-term as a stand-alone bill (Krutz, 2001).

However, the last word on surprise billing remains unspoken and future action on the issue may be inevitable. Although the federal protections enacted at the end of 2020 offer an improvement, the legislation included a number of compromises that may negatively affect consumers in the long run, including the exclusion of ground ambulances from billing protection and some potential loopholes that may particularly affect vulnerable consumers with limited health insurance literacy including individuals with low levels of education, lower levels of socio-economic status, older individuals and individuals from minority communities (Kim et al., 2013; Loewenstein et al., 2013; Bartholomae et al., 2016; Hoadley et al., 2020b). Furthermore, until implementation in 2022, the legislation will have to navigate the regulatory process where interest groups have long been known to disproportionately shape policy and pull regulatory outcomes toward their preferred positions (Haeder and Yackee, 2020b). The bill also extensively relies on states to enforce protections, raising concerns about state capacity and willingness to protect consumers (Haeder et al., 2019a). Moreover, the inflationary arbitration mechanism included may ultimately force consumers to pay higher premiums, which is in addition to the number of lawsuits the government will face by interested parties seeking to protect their profits.

\section{Previous research on surprise billing}

Although this intense interest group opposition had long hindered federal action, scholars have devoted considerable attention to understanding the economics of surprise billing in America. One of the most prominent areas of interest has been studying the incidence of surprise billing. Relying on claims data, existing research has shown that roughly $20 \%$ of emergency department visits lead to a surprise medical bill, whereas other research examining ambulatory surgery 
centers (ASCs) has shown that surprise medical bills occur in $8 \%$ of cases at in-network ASC facilities, after accounting for insurer payments (Garmon and Chartock, 2017; Adler et al., 2019; Claxton et al., 2019; Duffy et al., 2020). Surprise bills have been shown to extend into the inpatient and outpatient settings as well, often the result of including out-of-network anesthesiologists, radiologists, surgical assistants or surgeons as part of the care team (Cooper and Morton, 2016; Sun et al., 2019; Chhabra et al., 2020a; Cooper et al., 2020; Duffy et al., 2020). Surprise bills have also been shown to regularly result from transportation to medical care. Recent analyses have found that more than two-thirds of air ambulance transports are considered out-of-network by private insurers (U.S. Government Accountability Office, 2019; Chhabra et al., $2020 b$ ). In addition, research has shown that well over half of ground ambulance rides are considered out of network (Garmon and Chartock, 2017; Brown et al., 2020; Chhabra et al., 2020b).

There is also evidence to suggest that context and geography matter to surprise billing. For example, the percentage of in-network hospital admissions that include an out-of-network claim vary from a low of $1.7 \%$ in Minnesota to a high of $26.3 \%$ in Florida (Kennedy et al., 2019). Variations across cities can be even more dramatic, with scholars finding that surprise billing rates can be as high as $89 \%$ as in the case of McAllen, Texas, whereas cities such as Boulder, Colorado and South Bend, Indiana have surprise billing rates that are near zero (Cooper and Morton, 2016). Surprise bill experiences can also vary considerably across hospitals. Even as out-of-network billing is relatively rare at more than half of American hospitals, studies have identified that more than $90 \%$ of inpatient and emergency department admissions result in out-of-network bills at just over 15\% of U.S. hospitals (Adler et al., 2019; Cooper et al., 2019; Sun et al., 2019).

The size of surprise bills can be significant, and limited research on bill size shows considerable variation, with many Americans receiving far smaller surprise bills than those highlighted in accounts like the 'bill of the month' reporting series (Young et al., 2019). Yet, with research from the Federal Reserve indicating that $39 \%$ of Americans would struggle to cover an unexpected expense of just $\$ 400$, almost any surprise medical bill can cause considerable financial harm (Cooper and Morton, 2016; Federal Reserve System, 2019). This is especially true in light of the COVID-19 pandemic, which has increased unemployment and economic insecurity beyond the aforementioned 39\% identified by the Federal Reserve in 2019. Critically, the issue of surprise billing has gotten significantly worse over time. Between 2010 and 2016, the percentage of emergency department visits that resulted in an out-of-network medical bill increased from 32.3 to $42.8 \%$, with a concomitant $\$ 408$ increase in financial responsibility for patients (Kliff, 2019; Sun et al., 2019; Chhabra et al., 2020a). Similar increases have also been seen for inpatient admissions, with substantial growth in out-of-network bills (Sun et al., 2019).

Although this existing research has expanded our knowledge of surprise billing over the last several years, there are significant gaps in the literature. Notably, we need to learn more about the experiences of American consumers with surprise billing, how knowledgeable they are about the growing problem and who in the public is most concerned about the possibility of future surprise medical bills. Perhaps most importantly, it would be valuable for researchers, advocates and policymakers to understand the key drivers of public support or opposition to federal policy change in light of recent legislative efforts to find a more definitive long-term policy solution.

\section{Public opinion and health policy change}

In our effort to understand public experiences with surprise medical bills and public attitudes toward policy solutions to combat surprise bills, it is necessary to acknowledge an important body of existing research on public opinion toward efforts at policy change and that citizens' preference may influence governmental policy (Page and Shapiro, 1983; Gilens, 2009). This may be particularly true in the ever-contentious field of health policy (Brady and Kessler, 2010b). Indeed, 
there is ample evidence that public support, especially in the field of health care reform, is often high among the American public for vague policy solutions (Hacker, 1997; Brady and Kessler, 2010a; Starr, 2011). Yet, with many health policy proposals, the devil is, of course, in the details, and attitudes can diverge when the public is presented with specific solutions. As a prominent example, in the abstract, Americans have long supported 'health reform', but as past presidents have experienced, this type of support does not guarantee quick or ultimate success (Blumenthal and Morone, 2010). More generally, policymakers frequently express support for vaguely phrased policy proposals that are scarce on details, allowing them to further their re-election chances by position-taking without incurring actual costs (Mayhew, 2004).

However, hashing out the details of policy proposals often creates challenges for policymakers and policy advocates alike. For one, once policy details are established, winners and losers become apparent, and since responses to potential losses outweigh those to potential gains, policy losers are more likely to mobilize and invest resources to preserve the status quo (Wilson, 1973). Additionally, interest group campaigns to attack proposals, factual or not, often raise opposition among the public (Hacker, 1997). This may, particularly, be the case for policies where details are complex, as is the case for almost all health policies. We, hence, expect that a large number of Americans will support action by the federal government on surprise billing, but support will be much lower, and more varied, for specific policy proposals.

Notably, however, there are reasons to believe that policy change in the form of expanded protections for consumers is plausible in cases like surprise billing. Although entrenched interests who would stand to lose due to policy change typically win out because of the inherent status quo bias of the American political system with its myriad of veto points (Pressman and Wildavsky, 1973; Wilson, 1973; Tsebelis, 2002), surprise medical billing could represent a rare circumstance in which policymakers may have been able to overcome intense effort from oppositional groups. This is because policymakers are more likely to pursue policy change when target populations are viewed as deserving by the general public, when change is supported across political parties, and when policy change stands to produce good public policy that will aid politicians toward re-election (Mayhew, 1974/2004; Schneider and Ingram, 1997; Fenno, 2003; Cramer, 2016; Haeder et al., 2021). Policymakers are also more likely to follow public opinion for issues that affect citizens' everyday lives and when facing an upcoming election (Canes-Wrone and Shotts, 2004). The case of surprise medical billing meets these key criteria.

Interestingly, interest group influence and institutional roadblocks prevented congressional actors from passing a stand-alone bill despite these favorable conditions. As a result, supporters of federal actions had to resort to heresthetical devices (Riker, 1986) to overcome opposition. That is, congressional leadership had to include the billing protections in a massive, must-pass 2124 page omnibus appropriations bill (Krutz, 2001). Moreover, they had to make significant compromises that acknowledge the politically strong positions of the interest groups involved, such as the arbitration process which may do little to contain health care costs or the deference for state enforcement which traditionally has been less favorable for consumers (Haeder et al., 2019a). Indeed, as we pointed out above, the issue seems far from settled and may well require further congressional intervention to establish comprehensive protections for all Americans. Potential future policy action could be particularly likely during the Biden administration, given its focus on improving health access and equity and as politicians face future electorates if recent reforms prove insufficient. Importantly, the Biden Administration may also seek to move unilaterally, relying on its regulatory powers to move beyond the statutorily established protections (Haeder and Yackee, 2020a). In this regard, a better understanding of public sentiment and its potential impact on policy change requires additional research, which our study is poised to provide. 


\section{Study data and methods}

To study American experiences with surprise medical bills and their impact on public attitudes toward federal policy change, this study relies on an original national survey of American adults conducted from 9 to 19 September 2019. For the survey, we collected the responses of 4998 American adults (at a completion rate of 90\%) using Lucid's Fulcrum Academic tool, a survey platform that relies on quota sampling to provide nationally representative samples that closely mirror national benchmarks on a variety of demographic factors such as age, race, gender, education and income.

We paired Lucid's quota sampling with post-stratification weights to population benchmarks for gender, education, race, age and income to closely approximate the U.S. population. Importantly, research has demonstrated that demographic and experimental findings on Lucid closely match U.S. population benchmarks while outperforming convenience samples, which has led to widespread use of this platform in social science research (Callaghan et al., 2019; Coppock and McClellan, 2019; Wood and Porter, 2019; Lunz Trujillo et al., 2020; Motta and Callaghan, 2020; Haeder, 2021). Although our unweighted survey data closely match population benchmarks for key demographics (see Table A1), the inclusion of weights does improve our estimates and helps to ensure that our study of surprise bills accounts for the opinions of the U.S. population.

Before presenting survey respondents with questions about surprise medical bills, we introduced respondents to the topic of surprise billing by providing a brief description of the issue. Specifically, surprise bills were described as 'bills that patients with health insurance get for services they thought were covered by their insurance that asks them to pay more for health care than expected'. We paired this definition with the examples of surprise bills from the Kaiser Health News 'Bill of the Month' series. This definition and set of examples were provided to ensure that all respondents, regardless of their prior knowledge of surprise billing as a concept, could accurately answer our questions about their experiences and policy attitudes.

\subsection{Dependent variables}

After the background information preamble, respondents were asked several questions that serve as dependent variables in our analyses of surprise billing in the United States. First, to gage prior levels of knowledge about surprise medical bills before participating in the survey, we asked respondents whether they had ever heard of surprise medical bills before, with options for yes and no. Second, to understand the levels of public concern about surprise medical bills, we asked respondents how concerned they were about receiving a surprise medical bill, with options ranging from very concerned to not concerned at all on a 4-point scale.

Our analysis goes beyond prior research, which has explored Americans' experiences with surprise billing in the aggregate. To our knowledge, this is the first study that analyzes the correlates of Americans' opinions on potential policy solutions for the issue. We do so in two ways. First, we were interested in public support for federal policy action to stop surprise billing in the abstract. To capture abstract support, we simply asked respondents whether or not the federal government should take action to protect patients from having to pay the cost of surprise medical bills, with options for yes and no.

Second, we were interested in public opinion on specific policy proposals to curb surprise medical bills. For that reason, we also presented respondents with a set of specific policy proposals that have been in the public discourse surrounding surprise medical bills. Respondents were asked to check each policy they would support the federal government taking action on. These policy options reflect many of the major approaches proposed to address the issue. We specifically asked (1) whether in-network hospitals should be required to make sure that all doctors treating patients within their facility are also in-network, (2) whether payments for out-of-network physicians should be tied to reimbursement for other programs such as Medicare for the same 
treatment, (3) whether insurers and out-of-network physicians should be forced into arbitration to settle their disputes or, if unable to achieve agreement, to let a judge decide, (4) whether insurers should be forced to include a larger number of providers in their networks and (5) whether providers should be required to inform patients whether the recommended treatment is in-network and covered by their insurance company prior to treatment. Each specific policy proposal was coded as one if the respondent checked the policy to indicate they would support the federal government pursuing that policy change, and zero otherwise. Finally, we tested a composite measure that counts the number of specific policy proposals the individual thinks the federal government should take action on. This measure was tested to see if the same dynamics drove support for a single proposal as support for multiple proposals. As we do find consistency across both, results related to our composite measure are available in the Appendix. We selected this bifurcated approach (abstract and specific) regarding policy support, given the existing literature suggesting that support for reform in the abstract is generally high but far more opaque once broken down into specific policy proposals.

\subsection{Independent variables}

In addition to our dependent variables, our survey also included questions that serve as independent variables in our analyses. Our primary explanatory measure is respondents' past experience with surprise medical bills. To capture past experiences, we asked all respondents if they or a family member had ever received care from a doctor, hospital, lab or other health services provider that they thought would be covered by their insurance but led to an unexpected or surprise medical bill. Respondents were then asked a follow-up question about whether the person who had experienced the bill was the respondent themselves or a family member, and the size of the surprise medical bill received. Combined, these questions allow us to develop several alternative measures of past experience with surprise billing, which we will test as explanatory measures: personal surprise medical bill experience, family surprise bill experience, personal and family surprise bill experience, personal or family surprise bill experience (which we refer to as any surprise bill experience) and large surprise bill personal experience.

Our primary independent variable, personal surprise bill experience, is coded as one if the respondent themselves has ever gotten a surprise medical bill and coded as zero otherwise. Family surprise experience is coded as one if a family member of the respondent has received a surprise medical bill, and zero otherwise. This measure reflects the fact that even if an individual has not gotten a surprise bill themselves, a loved one confronting one could still change their levels of knowledge, concern and policy attitudes. We also capture two other related scenarios: one in which both the respondent and their family members have received surprise medical bills and one in which the respondent or a member of their family has received a bill. These measures serve as robustness checks and allow us to determine if different combinations of bill scenarios result in different policy attitudes. Finally, to capture large surprise bill experience, we code individuals as one's if the surprise bill they received was larger than $\$ 400$ - the cost threshold at which the Federal Reserve indicates that a considerable portion of Americans would struggle with an unexpected expense - and zero otherwise. We expect that regardless of the measure used, individuals with past surprise bill experience will be more likely to be knowledgeable about surprise billing, more concerned about the issue and more supportive of federal policy efforts to curb surprise billing.

We also include several insurance-related measures in our models, with separate indicators for respondents on Medicare, Medicaid or uninsured. These self-reported items were developed from a survey item asking respondents the type of insurance that they have. All three groups are largely, albeit not completely, shielded from surprise bills compared to the privately insured and we, thus, expect a negative relationship in our models. That is, because out-of-pocket costs are virtually non-existent for Medicaid recipients and severe limitations are put in place for Medicare beneficiaries, we expected them to be less exposed to surprise bills and thus be less knowledgeable, less 
concerned and less eager to support federal action. The uninsured, by definition, carry the entirety of their medical bills but should be less likely to be surprised because they expect considerable out-of-pocket costs.

Our analysis also includes a measure for gender (a dichotomous measure with female coded as one). As women make as much as $80 \%$ of health care decisions for the families, they should be more familiar with the health care system and its challenges (Matoff-Stepp et al., 2014). We expect the variable to be positively signed in all our models, indicating more familiarity with the issue, more concern and more support for federal action. Similarly, we also account for overall health (a 5-point measure ranging from poor to excellent) and age (and its square) in our models. Variables for both sicker and older individuals should also be positively signed toward higher knowledge, concern and policy support. We also expect a positive relationship for education (a 4-point measure with options ranging from less than high school to a bachelor's degree or higher) whereas we have no expectation for party identification (a 7-point item with higher scores indicating stronger Republican affiliation) in our analyses for knowledge and concern. However, we expect more conservative respondents to be more reticent to support federal action.

Our survey also accounts for additional control variables. Specifically, our analysis includes measures for Black and Hispanic racial and ethnicity status, and an interval-level measure for household income. Finally, some states have already taken action on the issue with potential effects on consumers. To account for the unique surprise billing environments in each state, our analysis includes a measure to capture balance billing protections enacted in each state. This 3-point measure was developed from the work of The Commonwealth Fund. It was scored as 2 if the respondent lived in a state rated as having a comprehensive approach to balance billing protections, 1 if their state was rated as having a limited approach to balance billing protections and 0 if their state had no balance billing protection (Kona, 2019).

\subsection{Data analysis plan}

In order to assess American knowledge of surprise billing and attitudes toward policy change, we estimated a number of logit models given the binary nature of the dependent variables. For our analysis of concern about surprise medical bills, we rely on ordinal logistic regression given the ordinal nature of that dependent variable. We tested a number of alternative specifications such as hierarchical logit models with random intercepts for all models presented here. Due to the non-linear nature of logit models, fixed effects may lead to an unexpected parameter problem and are thus not recommended (Neyman and Scott, 1948). The results of models with alternative specifications are analogous to the ones presented here and there are no indications that such modeling is warranted.

Given the difficulties in interpreting logit and ordered logit coefficients, we also present the average marginal effect (AME) for explanatory variables that are statistically significant at standard levels for each model in our analyses where appropriate (Cameron and Trivedi, 2010; Long and Freese, 2014). AMEs allow for a more straightforward interpretation of effect direction and size, similar to coefficients in ordinary least squares (OLS) regression, and are recommended for use in policy-relevant research (Cameron and Trivedi, 2010; Long and Freese, 2014). For indicator variables, we calculated AMEs for changes from 0 to 1 . For continuous variables, we calculated AMEs for changes by one standard deviation. Finally, for ordinal variables, we calculated AMEs for discrete changes by one unit. Tests for multicollinearity indicate that while age and its square are inherently correlated, multicollinearity is not a problem in our analysis.

\section{Study results}

We begin our analysis by exploring the frequency with which individuals receive surprise medical bills, which serves as a key independent variable in our analysis. We find that in our sample of 4998 Americans, 29.35\% (30.99\% unweighted) report having ever received a surprise medical bill 
and for almost $20 \%$ of Americans, the bill that they received exceeded $\$ 400$. When we expand our conceptualization of experience with surprise bills to include surprise bills received by family members, we find that 57.20\% (59.44\% unweighted) of Americans have either gotten a surprise bill themselves or had a family member receive one and seen the impact that these bills can have firsthand.

\subsection{Knowledge of surprise billing}

Although this information is valuable in helping us to understand the scope of the problem, it is equally important to understand how knowledgeable the public is about the issue. After all, it is difficult to plan for possible medical bills (let alone demand policy change) if you don't know that surprise billing even exists. To assess public knowledge of surprise medical bills, we asked respondents if they had ever heard of surprise medical bills before taking our survey and estimate a standard logit model in Table 1 where a score of one indicates that the respondent had heard of surprise medical bills before.

Our results in Table 1 suggest that knowledge of surprise medical bills is generally high, with an average prediction for having prior knowledge of surprise bills at 0.679 on a zero to one scale. This finding suggests that almost one-third of the population is largely unaware of the growing problem and that as such, large segments of the public have been at risk of being blindsided by future bills. Due to significant churning between programs (Short et al., 2003; Vistnes et al., 2017), this even includes beneficiaries of Medicaid and Medicare who may lose those protections when they enter another market (Boccuti, 2016). Moreover, not all Medicare services are protected from balance billing (Boccuti, 2016). Our analyses in Table 1 across models further shows that knowledge of surprise medical bills is consistently predicted by four of our explanatory measures, with education and past surprise bill experience serving as positive predictors of knowledge and being uninsured and Hispanic status serving as negative predictors. Critically, our past experience measure increases knowledge regardless of how it is specified.

In model 1 , we find that personally experiencing a surprise medical bill increases the probability of having heard about the issue by 0.161 on a zero to one scale $(p=0.000)$ compared to those who had not previously experienced one. In addition, we find that a 1-unit increase in education increases the probability of knowing about surprise medical bills by $0.051(\mathrm{p}=0.000)$. Conversely, being uninsured and Hispanic reduce the probability of knowledge of surprise medical bills by $0.094(\mathrm{p}=0.001)$ and $0.079(\mathrm{p}=0.008)$, respectively. When we replace personal experience with surprise bills with an alternative measure accounting for family surprise bill experience in model 2, we find a similar pattern of results. In particular, we find that education and experience remain positive and significant predictors of knowledge whereas uninsured status and being Hispanic remain negative and significant predictors. Notably, we find that previously experiencing or having a family member experience a surprise medical bill increases the probability of having heard about the issue by $0.104(\mathrm{p}=0.000)$ compared to those who had not experienced one in their families. In cases where both a family member and the respondent received a surprise bill, the probability of knowledge increases by $0.178(p=0.000)$, whereas it increases by $0.264(\mathrm{p}=0.000)$ for any experience with surprise billing. Finally, we also estimated a model that accounted for the size of the surprise bill using an indicator to represent whether the respondents received a bill in excess of $\$ 400$. Once more, the same pattern is apparent, with having received an unexpected bill of $\$ 400$ or larger, increasing the probability of having heard of the issue by $0.176(\mathrm{p}=0.000)$.

\subsection{Concern about surprise billing}

Beyond experience with and knowledge of surprise billing, we also assessed how concerned Americans are about the possibility of receiving a surprise medical bill in the future. In this analysis, our dependent variable was a 4-point measure for the level of concern, and we rely on 
Table 1. Predictors of knowledge of surprise bills among Americans

\begin{tabular}{|c|c|c|c|c|c|c|c|c|c|c|}
\hline \multirow[b]{2}{*}{ Variables } & \multicolumn{2}{|c|}{ (1) } & \multicolumn{2}{|c|}{$(2)$} & \multicolumn{2}{|c|}{ (3) } & \multicolumn{2}{|c|}{ (4) } & \multicolumn{2}{|c|}{ (5) } \\
\hline & Self & AME & Family & AME & Both & AME & Any & AME & Size & AME \\
\hline \multirow[t]{2}{*}{ Personal surprise bill } & $0.82^{\star \star \star}$ & 0.161 & & & & & & & & \\
\hline & $(0.105)$ & $(0.000)$ & & & & & & & & \\
\hline \multirow[t]{2}{*}{ Family surprise bill } & & & $0.53^{\star \star \star}$ & 0.104 & & & & & & \\
\hline & & & $(0.111)$ & $(0.000)$ & & & & & & \\
\hline \multirow[t]{2}{*}{ Both personal and family surprise bill } & & & & & $1.03^{\star \star \star}$ & 0.178 & & & & \\
\hline & & & & & $(0.196)$ & $(0.000)$ & & & & \\
\hline \multirow[t]{2}{*}{ Any surprise bill } & & & & & & & $1.27^{\star \star \star}$ & 0.264 & & \\
\hline & & & & & & & $(0.092)$ & $(0.000)$ & & \\
\hline \multirow[t]{2}{*}{ Large surprise bill } & & & & & & & & & $0.96^{\star \star \star}$ & 0.76 \\
\hline & & & & & & & & & $(0.137)$ & $(0.000)$ \\
\hline \multirow[t]{2}{*}{ Medicare } & 0.05 & & 0.08 & & 0.05 & & 0.05 & & 0.11 & \\
\hline & $(0.135)$ & & $(0.133)$ & & $(0.133)$ & & $(0.139)$ & & $(0.134)$ & \\
\hline \multirow[t]{2}{*}{ Medicaid } & -0.13 & & -0.15 & & -0.14 & & -0.14 & & -0.10 & \\
\hline & $(0.135)$ & & $(0.133)$ & & $(0.133)$ & & $(0.137)$ & & $(0.132)$ & \\
\hline \multirow[t]{2}{*}{ Uninsured } & $-0.44^{\star \star \star}$ & -0.094 & $-0.50^{\star \star \star}$ & -0.111 & $-0.47^{\star \star \star}$ & -0.103 & $-0.46^{\star \star \star}$ & -0.093 & $-0.45^{\star \star \star}$ & -0.098 \\
\hline & $(0.128)$ & $(0.001)$ & $(0.126)$ & $(0.000)$ & $(0.126)$ & $(0.000)$ & $(0.132)$ & $(0.001)$ & $(0.128)$ & $(0.001)$ \\
\hline \multirow[t]{2}{*}{ Overall health } & -0.07 & & $-0.08^{\star}$ & -0.016 & -0.07 & & $-0.08^{*}$ & & -0.05 & \\
\hline & $(0.047)$ & & $(0.046)$ & $(0.096)$ & $(0.046)$ & & $(0.048)$ & & $(0.047)$ & \\
\hline \multirow[t]{2}{*}{ Education } & $0.26^{\star \star \star}$ & 0.051 & $0.27^{\star \star \star}$ & 0.054 & $0.29^{\star \star \star}$ & 0.057 & $0.25^{\star \star \star}$ & 0.047 & $0.27^{\star \star \star}$ & 0.054 \\
\hline & $(0.057)$ & $(0.000)$ & $(0.055)$ & $(0.000)$ & $(0.055)$ & $(0.000)$ & $(0.059)$ & $(0.000)$ & $(0.055)$ & $(0.000)$ \\
\hline \multirow[t]{2}{*}{ Female } & -0.07 & & -0.10 & & -0.12 & & -0.12 & & -0.07 & \\
\hline & $(0.090)$ & & $(0.089)$ & & $(0.089)$ & & $(0.092)$ & & $(0.089)$ & \\
\hline
\end{tabular}




\begin{tabular}{|c|c|c|c|c|c|c|c|c|c|c|}
\hline \multirow[t]{2}{*}{ Household income } & \multicolumn{2}{|l|}{0.01} & \multicolumn{2}{|l|}{0.00} & \multicolumn{2}{|l|}{0.00} & \multicolumn{2}{|l|}{0.01} & \multicolumn{2}{|l|}{0.00} \\
\hline & $(0.008)$ & & $(0.008)$ & & $(0.008)$ & & $(0.008)$ & & $(0.008)$ & \\
\hline \multirow[t]{2}{*}{ Party identification } & 0.00 & & 0.01 & & 0.00 & & 0.01 & & 0.01 & \\
\hline & $(0.020)$ & & $(0.020)$ & & $(0.020)$ & & $(0.021)$ & & $(0.020)$ & \\
\hline \multirow[t]{2}{*}{ Age } & 0.00 & & 0.01 & & 0.01 & & 0.00 & & 0.00 & \\
\hline & $(0.016)$ & & $(0.016)$ & & $(0.016)$ & & $(0.017)$ & & $(0.016)$ & \\
\hline \multirow[t]{2}{*}{ Age squared } & -0.00 & & -0.00 & & -0.00 & & 0.00 & & -0.00 & \\
\hline & $(0.000)$ & & $(0.000)$ & & $(0.000)$ & & $(0.000)$ & & $(0.000)$ & \\
\hline \multirow[t]{2}{*}{ Black } & -0.10 & & -0.04 & & -0.08 & & -0.10 & & -0.06 & \\
\hline & $(0.133)$ & & $(0.127)$ & & $(0.127)$ & & $(0.137)$ & & $(0.129)$ & \\
\hline \multirow[t]{2}{*}{ Hispanic } & $-0.37^{\star \star \star}$ & -0.079 & $-0.32^{\star \star}$ & -0.069 & $-0.29^{\star \star}$ & -0.062 & $-0.40^{\star \star \star}$ & -0.080 & $-0.32^{\star \star}$ & -0.069 \\
\hline & $(0.135)$ & $(0.008)$ & $(0.131)$ & $(0.019)$ & $(0.133)$ & $(0.035)$ & $(0.139)$ & $(0.005)$ & $(0.134)$ & $(0.021)$ \\
\hline \multirow[t]{2}{*}{ Balance bill protections } & -0.07 & & -0.08 & & -0.07 & & -0.06 & & -0.07 & \\
\hline & $(0.053)$ & & $(0.052)$ & & $(0.052)$ & & $(0.054)$ & & $(0.053)$ & \\
\hline \multirow[t]{2}{*}{ Constant } & 0.20 & & 0.12 & & 0.12 & & -0.36 & & 0.14 & \\
\hline & $(0.441)$ & & $(0.437)$ & & $(0.438)$ & & $(0.458)$ & & $(0.437)$ & \\
\hline Observations & 4424 & & 4440 & & 4440 & & 4424 & & 4440 & \\
\hline$R^{2}$ & 0.083 & & 0.057 & & 0.65 & & 0.145 & & 0.082 & \\
\hline Average prediction & & 0.679 & & 0.679 & & 0.679 & & 0.679 & & 0.679 \\
\hline
\end{tabular}

Note: Robust standard errors in parentheses.

${ }^{\star * \star} p<0.01,{ }^{\star *} p<0.05,{ }^{*} p<0.10$. 
ordinal logistic regression for our analysis. The average predictions for the four levels of concern, i.e. from not concerned at all to very concerned, amount to $0.114,0.186,0.304$ and 0.396 . In other words, the average probability that respondents fall into the somewhat or very concerned categories combined amounts to a substantial 0.700 on a zero to one scale.

Our findings in Table 2 show that measures accounting for personal experience with surprise billing, level of education, gender, income and Medicaid status are statistically significant predictors of concern about surprise bills. In particular, past experiences with surprise billing, being a woman, and increased education all increase concern about surprise billing, whereas higher levels of income and being on Medicaid are associated with being less concerned. The influence of past experience with surprise bills is particularly pronounced, as it increases the probability of being very concerned by 0.180 when exploring personal surprise bill experience. When we replace this measure with the family based experience, the corresponding AME is $0.048(\mathrm{p}=0.020)$ whereas it is $0.222(\mathrm{p}=0.000)$ for cases with personal and family experience with surprise bills and 0.244 $(\mathrm{p}=0.000)$ for any experience with surprise bills. Finally, when we replace it with the indicator for bills larger than $\$ 400$, the increase amounts to $0.187(\mathrm{p}=0.000)$.

\subsection{General support for federal action}

Although the analysis to this point has provided important information about the correlates of American knowledge of surprise medical bills and their concerns about them, it is critical to explore American policy attitudes surrounding the issue. For that reason, our survey also asked respondents whether they thought the federal government should address the issue. As shown in Table 3, we find that the average prediction for support for federal action on surprise medical bills is remarkably high - at 0.845 . The results also highlight the importance of past experiences with surprise medical bills to public attitudes toward federal policy action in the abstract. Model 11 demonstrates that individuals who have received a surprise medical bill previously are significantly more likely to support federal policy action, increasing the probability of support by an additional $0.063(\mathrm{p}=0.000)$. This finding also holds in model 14 when utilizing personal or family experience as the measure of past surprise bill exposure $(0.077, p=0.000)$ or large bills in model $15(0.061, \mathrm{p}=0.000)$. Notably, we do not find statistically significant differences in support when examining family only experience or personal and family experience. However, in the case of a surprise bill for a family member, the effect size just misses standard levels of statistical significance $(p=0.122)$. Beyond past experiences, we additionally find that Blacks are consistently more supportive of government action on surprise bills across all models. The same holds as the strength of Republican Party affiliation increases: support for federal action significantly declines in all five models.

\subsection{Support for specific policy actions}

Based on the findings presented in Table 3, it is apparent that Americans would like to see Congress take action to protect consumers from surprise bills. Yet, as we mentioned above, the devil is often in the details. Table 4 presents our findings for the five federal policy proposals included in our survey: (1) whether in-network hospitals should be required to make sure that all doctors treating patients within their facility are also in-network, (2) whether payments for out-of-network physicians should be tied to reimbursement for other programs, (3) whether insurers and out-of-network physicians should be forced into arbitration, (4) whether insurers should be forced to include a larger number of providers in their networks and (5) whether providers should be required to inform patients whether the recommended treatment is in-network and covered by their insurance company. We only present the models estimated with the variable

indicating a personal experience with surprise bills. Models using the other experience variables are presented in the Appendix. 
Table 2. Concern about surprise bills among Americans

\begin{tabular}{|c|c|c|c|c|c|c|c|c|c|}
\hline \multirow[b]{3}{*}{ Variables } & \multicolumn{5}{|l|}{ (6) } & \multirow{3}{*}{$\begin{array}{c}\text { (7) } \\
\text { Family }\end{array}$} & \multirow{3}{*}{$\begin{array}{c}\text { (8) } \\
\text { Both }\end{array}$} & \multirow{3}{*}{$\begin{array}{l}\text { (9) } \\
\text { Any }\end{array}$} & \multirow{3}{*}{$\begin{array}{l}(10) \\
\text { Size }\end{array}$} \\
\hline & \multirow[b]{2}{*}{ Self } & \multicolumn{4}{|c|}{ AME } & & & & \\
\hline & & Not at all & A little & Somewhat & Very & & & & \\
\hline \multirow[t]{2}{*}{ Personal surprise bill } & $0.75^{\star \star \star}$ & -0.065 & -0.079 & -0.036 & 0.180 & & & & \\
\hline & $(0.082)$ & $(0.000)$ & $(0.000)$ & $(0.000)$ & $(0.000)$ & & & & \\
\hline \multirow[t]{2}{*}{ Family surprise bill } & & & & & & $0.20^{\star \star}$ & & & \\
\hline & & & & & & $(0.086)$ & & & \\
\hline \multirow[t]{2}{*}{ Both personal and family surprise bill } & & & & & & & $0.92^{\star \star \star}$ & & \\
\hline & & & & & & & $(0.141)$ & & \\
\hline \multirow[t]{2}{*}{ Any surprise bill } & & & & & & & & $1.08^{\star \star \star}$ & \\
\hline & & & & & & & & $(0.078)$ & \\
\hline \multirow[t]{2}{*}{ Large surprise bill } & & & & & & & & & $0.77^{\star \star \star}$ \\
\hline & & & & & & & & & $(0.095)$ \\
\hline \multirow[t]{2}{*}{ Medicare } & -0.10 & & & & & -0.09 & -0.12 & -0.11 & -0.06 \\
\hline & $(0.116)$ & & & & & $(0.114)$ & $(0.114)$ & $(0.117)$ & $(0.115)$ \\
\hline \multirow[t]{2}{*}{ Medicaid } & $-0.27^{\star \star}$ & 0.029 & 0.028 & 0.004 & -0.061 & $-0.27^{\star \star}$ & $-0.27^{\star \star}$ & $-0.29^{\star \star}$ & $-0.24^{\star \star}$ \\
\hline & $(0.117)$ & $(0.032)$ & $(0.017)$ & $(0.004)$ & $(0.016)$ & $(0.116)$ & $(0.119)$ & $(0.116)$ & $(0.117)$ \\
\hline \multirow[t]{2}{*}{ Uninsured } & -0.14 & & & & & -0.17 & -0.15 & -0.14 & -0.13 \\
\hline & $(0.109)$ & & & & & $(0.109)$ & $(0.110)$ & $(0.110)$ & $(0.110)$ \\
\hline \multirow[t]{2}{*}{ Overall health } & -0.00 & & & & & -0.02 & -0.01 & -0.00 & 0.00 \\
\hline & $(0.041)$ & & & & & $(0.040)$ & $(0.041)$ & $(0.040)$ & $(0.041)$ \\
\hline \multirow[t]{2}{*}{ Education } & $0.14^{\star \star \star}$ & -0.014 & -0.015 & -0.005 & 0.033 & $0.15^{\star \star \star}$ & $0.17^{\star \star \star}$ & $0.13^{\star \star \star}$ & $0.15^{\star \star \star}$ \\
\hline & $(0.049)$ & $(0.003)$ & $(0.003)$ & $(0.009)$ & $(0.003)$ & $(0.048)$ & $(0.048)$ & $(0.050)$ & $(0.049)$ \\
\hline
\end{tabular}


Table 2. (Continued.)

\begin{tabular}{|c|c|c|c|c|c|c|c|c|c|}
\hline \multirow[b]{3}{*}{ Variables } & \multicolumn{5}{|l|}{ (6) } & \multirow{3}{*}{$\begin{array}{c}\text { (7) } \\
\text { Family }\end{array}$} & \multirow{3}{*}{$\begin{array}{l}\text { (8) } \\
\text { Both }\end{array}$} & \multirow{3}{*}{$\begin{array}{l}\text { (9) } \\
\text { Any }\end{array}$} & \multirow{3}{*}{$\begin{array}{l}\text { (10) } \\
\text { Size }\end{array}$} \\
\hline & \multirow[b]{2}{*}{ Self } & \multicolumn{4}{|c|}{ AME } & & & & \\
\hline & & Not at all & A little & Somewhat & Very & & & & \\
\hline \multirow[t]{2}{*}{ Female } & $0.17^{\star *}$ & -0.017 & -0.018 & -0.004 & 0.04 & $0.16^{\star \star}$ & $0.14^{\star}$ & $0.14^{\star}$ & $0.18^{\star \star}$ \\
\hline & $(0.075)$ & $(0.023)$ & $(0.020)$ & $(0.029)$ & $(0.021)$ & $(0.074)$ & $(0.074)$ & $(0.075)$ & $(0.075)$ \\
\hline \multirow[t]{2}{*}{ Household income } & $-0.01^{\star}$ & 0.001 & 0.001 & 0.000 & -0.003 & $-0.01^{*}$ & $-0.01^{\star \star}$ & $-0.01^{\star \star}$ & $-0.01^{*}$ \\
\hline & $(0.006)$ & $(0.062)$ & $(0.057)$ & $(0.038)$ & $(0.054)$ & $(0.006)$ & $(0.006)$ & $(0.006)$ & $(0.006)$ \\
\hline \multirow[t]{2}{*}{ Party identification } & -0.02 & & & & & -0.03 & -0.03 & -0.02 & -0.02 \\
\hline & $(0.017)$ & & & & & $(0.017)$ & $(0.017)$ & $(0.017)$ & $(0.017)$ \\
\hline \multirow[t]{2}{*}{ Age } & 0.02 & & & & & $0.03^{\star \star}$ & $0.03^{\star \star}$ & 0.02 & 0.02 \\
\hline & $(0.013)$ & & & & & $(0.013)$ & $(0.013)$ & $(0.013)$ & $(0.013)$ \\
\hline \multirow[t]{2}{*}{ Age squared } & $-0.00^{\star}$ & & & & & $-0.00^{\star \star}$ & $-0.00^{\star \star}$ & -0.00 & $-0.00^{\star}$ \\
\hline & $(0.000)$ & & & & & $(0.000)$ & $(0.000)$ & $(0.000)$ & $(0.000)$ \\
\hline \multirow[t]{2}{*}{ Black } & 0.05 & & & & & 0.07 & 0.05 & 0.06 & 0.06 \\
\hline & $(0.121)$ & & & & & $(0.117)$ & $(0.117)$ & $(0.124)$ & $(0.119)$ \\
\hline \multirow[t]{2}{*}{ Hispanic } & 0.10 & & & & & 0.13 & 0.17 & 0.11 & 0.14 \\
\hline & $(0.111)$ & & & & & $(0.111)$ & $(0.113)$ & $(0.113)$ & $(0.111)$ \\
\hline \multirow[t]{2}{*}{ Balance bill protections } & 0.04 & & & & & 0.02 & 0.03 & 0.06 & 0.03 \\
\hline & $(0.043)$ & & & & & $(0.043)$ & $(0.043)$ & $(0.044)$ & $(0.043)$ \\
\hline Observations & 4426 & & & & & 4442 & 4442 & 4426 & 4442 \\
\hline \multicolumn{10}{|l|}{$R^{2}$} \\
\hline Average prediction & & 0.114 & 0.186 & 0.304 & 0.396 & & & & \\
\hline
\end{tabular}

Note: Robust standard errors in parentheses.

${ }^{* \star *} p<0.01,{ }^{* \star} p<0.05,{ }^{*} p<0.10$ 
Table 3. Attitudes on whether or not the federal government should take action on surprise bills

\begin{tabular}{|c|c|c|c|c|c|c|c|c|c|c|}
\hline \multirow[b]{2}{*}{ Variables } & \multicolumn{2}{|c|}{ (11) } & \multicolumn{2}{|c|}{$(12)$} & \multicolumn{2}{|c|}{ (13) } & \multicolumn{2}{|c|}{ (14) } & \multicolumn{2}{|c|}{ (15) } \\
\hline & Self & AME & Family & AME & Both & AME & Any & AME & Size & AME \\
\hline \multirow[t]{2}{*}{ Personal surprise bill } & $0.54^{\star \star \star}$ & 0.063 & & & & & & & & \\
\hline & $(0.136)$ & $(0.000)$ & & & & & & & & \\
\hline \multirow[t]{2}{*}{ Family surprise bill } & & & 0.22 & & & & & & & \\
\hline & & & $(0.147)$ & & & & & & & \\
\hline \multirow[t]{2}{*}{ Both personal and family surprise bill } & & & & & 0.15 & & & & & \\
\hline & & & & & $(0.240)$ & & & & & \\
\hline \multirow[t]{2}{*}{ Any surprise bill } & & & & & & & $0.60^{\star \star \star}$ & 0.077 & & \\
\hline & & & & & & & $(0.117)$ & $(0.000)$ & & \\
\hline \multirow[t]{2}{*}{ Large surprise bill } & & & & & & & & & $0.54^{\star \star \star}$ & 0.061 \\
\hline & & & & & & & & & $(0.176)$ & $(0.000)$ \\
\hline \multirow[t]{2}{*}{ Medicare } & 0.11 & & 0.12 & & 0.11 & & 0.10 & & 0.14 & \\
\hline & $(0.171)$ & & $(0.169)$ & & $(0.169)$ & & $(0.171)$ & & $(0.170)$ & \\
\hline \multirow[t]{2}{*}{ Medicaid } & 0.02 & & -0.01 & & -0.01 & & 0.02 & & 0.02 & \\
\hline & $(0.183)$ & & $(0.183)$ & & $(0.183)$ & & $(0.186)$ & & $(0.183)$ & \\
\hline \multirow[t]{2}{*}{ Uninsured } & -0.26 & & $-0.32^{\star \star}$ & -0.044 & $-0.32^{\star}$ & -0.043 & -0.26 & & $-0.30^{\star}$ & -0.041 \\
\hline & $(0.164)$ & & $(0.164)$ & $(0.064)$ & $(0.164)$ & $(0.068)$ & $(0.164)$ & & $(0.164)$ & $(0.081)$ \\
\hline \multirow[t]{2}{*}{ Overall health } & -0.07 & & -0.06 & & -0.06 & & -0.07 & & -0.05 & \\
\hline & $(0.064)$ & & $(0.064)$ & & $(0.064)$ & & $(0.064)$ & & $(0.065)$ & \\
\hline \multirow[t]{2}{*}{ Education } & -0.08 & & -0.05 & & -0.05 & & -0.09 & & -0.06 & \\
\hline & $(0.073)$ & & $(0.072)$ & & $(0.072)$ & & $(0.073)$ & & $(0.072)$ & \\
\hline \multirow[t]{2}{*}{ Female } & 0.06 & & 0.02 & & 0.03 & & 0.03 & & 0.04 & \\
\hline & $(0.116)$ & & $(0.116)$ & & $(0.115)$ & & $(0.117)$ & & $(0.116)$ & \\
\hline
\end{tabular}




\begin{tabular}{|c|c|c|c|c|c|c|c|c|c|c|}
\hline \multirow[b]{2}{*}{ Variables } & \multicolumn{2}{|c|}{ (11) } & \multicolumn{2}{|c|}{ (12) } & \multicolumn{2}{|c|}{ (13) } & \multicolumn{2}{|c|}{ (14) } & \multicolumn{2}{|c|}{ (15) } \\
\hline & Self & AME & Family & AME & Both & AME & Any & AME & Size & AME \\
\hline \multirow[t]{2}{*}{ Household income } & -0.00 & & -0.01 & & -0.01 & & -0.00 & & -0.01 & \\
\hline & $(0.009)$ & & $(0.010)$ & & $(0.010)$ & & $(0.009)$ & & $(0.010)$ & \\
\hline \multirow[t]{2}{*}{ Party identification } & $-0.18^{\star \star \star}$ & -0.023 & $-0.17^{\star \star \star}$ & -0.023 & $-0.17^{\star \star \star}$ & -0.023 & $-0.18^{\star \star \star}$ & -0.023 & $-0.17^{\star \star \star}$ & -0.023 \\
\hline & $(0.025)$ & $(0.000)$ & $(0.025)$ & $(0.000)$ & $(0.025)$ & $(0.000)$ & $(0.025)$ & $(0.000)$ & $(0.025)$ & $(0.000)$ \\
\hline \multirow[t]{2}{*}{ Age } & 0.03 & & $0.04^{\star}$ & & $0.04^{*}$ & & $0.03^{*}$ & & $0.04^{\star}$ & \\
\hline & $(0.021)$ & & $(0.021)$ & & $(0.021)$ & & $(0.021)$ & & $(0.020)$ & \\
\hline \multirow[t]{2}{*}{ Age squared } & $-0.00^{\star \star}$ & & $-0.00^{\star *}$ & & $-0.00^{\star \star}$ & & $-0.00^{*}$ & & $-0.00^{* *}$ & \\
\hline & $(0.000)$ & & $(0.000)$ & & $(0.000)$ & & $(0.000)$ & & $(0.000)$ & \\
\hline \multirow[t]{2}{*}{ Black } & $0.56^{\star \star \star}$ & 0.061 & $0.60^{\star \star \star}$ & 0.065 & $0.60^{\star \star \star}$ & 0.065 & $0.57^{\star \star \star}$ & 0.061 & $0.60^{\star \star \star}$ & 0.65 \\
\hline & $(0.208)$ & $(0.002)$ & $(0.207)$ & $(0.001)$ & $(0.206)$ & $(0.001)$ & $(0.209)$ & $(0.001)$ & $(0.206)$ & $(0.001)$ \\
\hline \multirow[t]{2}{*}{ Hispanic } & -0.28 & & -0.25 & & -0.24 & & -0.28 & & -0.25 & \\
\hline & $(0.181)$ & & $(0.181)$ & & $(0.183)$ & & $(0.181)$ & & $(0.181)$ & \\
\hline \multirow[t]{2}{*}{ Balance bill protections } & 0.10 & & 0.10 & & 0.10 & & 0.11 & & 0.10 & \\
\hline & $(0.067)$ & & $(0.067)$ & & $(0.067)$ & & $(0.067)$ & & $(0.067)$ & \\
\hline \multirow[t]{2}{*}{ Constant } & $2.15^{\star \star \star}$ & & $2.10^{\star \star *}$ & & $2.12^{\star \star \star}$ & & $1.94^{\star \star \star}$ & & $2.08^{\star \star \star}$ & \\
\hline & $(0.596)$ & & $(0.596)$ & & $(0.595)$ & & $(0.606)$ & & $(0.591)$ & \\
\hline Observations & 4413 & & 4429 & & 4429 & & 4413 & & 4429 & \\
\hline$R^{2}$ & 0.107 & & 0.092 & & 0.091 & & 0.113 & & 0.102 & \\
\hline Average prediction & & 0.845 & & 0.845 & & 0.845 & & 0.845 & & 0.845 \\
\hline
\end{tabular}

Table 3. (Continued.)

Note: Robust standard errors in parentheses.

${ }^{\star \star \star} p<0.01,{ }^{\star \star} p<0.05,{ }^{*} p<0.10$ 
Table 4. Support for specific policies to mitigate surprise billing - personal experience

\begin{tabular}{|c|c|c|c|c|c|c|c|c|c|c|}
\hline \multirow[b]{2}{*}{ Variables } & \multicolumn{2}{|l|}{ (16) } & \multicolumn{2}{|l|}{ (17) } & \multicolumn{2}{|c|}{ (18) } & \multicolumn{2}{|l|}{ (19) } & \multicolumn{2}{|l|}{ (20) } \\
\hline & In-network facilities & AME & Reference pricing & AME & Arbitration & AME & Broader networks & AME & Inform patients & AME \\
\hline \multirow[t]{2}{*}{ Personal surprise } & -0.07 & & 0.01 & & 0.06 & & 0.08 & & -0.14 & \\
\hline & $(0.090)$ & & $(0.093)$ & & $(0.100)$ & & $(0.089)$ & & $(0.092)$ & \\
\hline \multirow[t]{2}{*}{ Medicare } & $-0.25^{\star \star}$ & -0.058 & 0.14 & & -0.11 & & $-0.21^{\star}$ & -0.046 & $-0.29^{\star \star}$ & -0.064 \\
\hline & $(0.121)$ & $(0.035)$ & $(0.126)$ & & $(0.135)$ & & $(0.121)$ & $(0.079)$ & $(0.129)$ & $(0.023)$ \\
\hline \multirow[t]{2}{*}{ Medicaid } & $-0.33^{\star \star}$ & -0.077 & -0.10 & & 0.01 & & -0.19 & & -0.18 & \\
\hline & $(0.130)$ & $(0.011)$ & $(0.131)$ & & $(0.150)$ & & $(0.128)$ & & $(0.130)$ & \\
\hline \multirow[t]{2}{*}{ Uninsured } & $-0.33^{\star \star \star}$ & -0.077 & -0.14 & & -0.13 & & $-0.30^{\star \star}$ & -0.066 & $-0.33^{\star \star \star}$ & -0.075 \\
\hline & $(0.123)$ & $(0.007)$ & $(0.126)$ & & $(0.139)$ & & $(0.124)$ & $(0.013)$ & $(0.121)$ & $(0.008)$ \\
\hline \multirow[t]{2}{*}{ Overall health } & $-0.11^{\star \star}$ & -0.025 & -0.06 & & -0.02 & & $-0.18^{\star \star \star}$ & -0.039 & $-0.14^{\star \star \star}$ & -0.032 \\
\hline & $(0.042)$ & $(0.010)$ & $(0.043)$ & & $(0.048)$ & & $(0.042)$ & $(0.000)$ & $(0.043)$ & $(0.001)$ \\
\hline \multirow[t]{2}{*}{ Education } & $0.09^{\star}$ & 0.020 & $0.17^{\star \star \star}$ & 0.037 & -0.02 & & 0.08 & & $0.10^{*}$ & 0.023 \\
\hline & $(0.052)$ & $(0.091)$ & $(0.057)$ & $(0.003)$ & $(0.062)$ & & $(0.052)$ & & $(0.053)$ & $(0.053)$ \\
\hline \multirow[t]{2}{*}{ Female } & $0.22^{\star \star \star}$ & 0.051 & -0.10 & & -0.14 & & $0.23^{\star \star \star}$ & 0.052 & $0.23^{\star \star \star}$ & 0.051 \\
\hline & $(0.083)$ & $(0.009)$ & $(0.086)$ & & $(0.094)$ & & $(0.084)$ & $(0.006)$ & $(0.085)$ & $(0.008)$ \\
\hline \multirow[t]{2}{*}{ Household income } & 0.00 & & -0.00 & & $0.02^{\star \star}$ & 0.003 & -0.01 & & 0.01 & \\
\hline & $(0.007)$ & & $(0.007)$ & & $(0.008)$ & $(0.034)$ & $(0.007)$ & & $(0.008)$ & \\
\hline \multirow[t]{2}{*}{ Party identification } & -0.02 & & $-0.07^{\star \star \star}$ & -0.015 & -0.03 & & $-0.04^{\star \star}$ & -0.009 & -0.00 & \\
\hline & $(0.019)$ & & $(0.020)$ & $(0.000)$ & $(0.021)$ & & $(0.019)$ & $(0.032)$ & $(0.019)$ & \\
\hline \multirow[t]{2}{*}{ Age } & 0.00 & & -0.02 & & -0.01 & & 0.01 & & $-0.06^{\star \star \star}$ & \\
\hline & $(0.016)$ & & $(0.016)$ & & $(0.017)$ & & $(0.015)$ & & $(0.017)$ & \\
\hline \multirow[t]{2}{*}{ Age squared } & 0.00 & & 0.00 & & 0.00 & & -0.00 & & $0.00^{\star \star \star}$ & \\
\hline & $(0.000)$ & & $(0.000)$ & & $(0.000)$ & & $(0.000)$ & & $(0.000)$ & \\
\hline
\end{tabular}




\begin{tabular}{|c|c|c|c|c|c|c|c|c|c|c|}
\hline \multirow[b]{2}{*}{ Variables } & \multicolumn{2}{|l|}{ (16) } & \multicolumn{2}{|l|}{ (17) } & \multicolumn{2}{|c|}{ (18) } & \multicolumn{2}{|l|}{ (19) } & \multicolumn{2}{|l|}{ (20) } \\
\hline & In-network facilities & AME & Reference pricing & AME & Arbitration & AME & Broader networks & AME & Inform patients & AME \\
\hline \multirow[t]{2}{*}{ Black } & $-0.26^{\star \star}$ & -0.061 & -0.12 & & -0.02 & & -0.10 & & $-0.32^{\star \star \star}$ & -0.073 \\
\hline & $(0.129)$ & $(0.042)$ & $(0.135)$ & & $(0.144)$ & & $(0.127)$ & & $(0.124)$ & $(0.011)$ \\
\hline \multirow[t]{2}{*}{ Hispanic } & -0.18 & & -0.02 & & $-0.38^{\star *}$ & -0.067 & $-0.24^{\star}$ & & $-0.46^{\star \star \star}$ & -0.105 \\
\hline & $(0.131)$ & & $(0.136)$ & & $(0.155)$ & $(0.009)$ & $(0.134)$ & & $(0.130)$ & $(0.000)$ \\
\hline \multirow[t]{2}{*}{ Balance bill protections } & $0.10^{\star \star}$ & 0.024 & 0.03 & & 0.07 & & -0.04 & & 0.01 & \\
\hline & $(0.049)$ & $(0.039)$ & $(0.050)$ & & $(0.056)$ & & $(0.049)$ & & $(0.050)$ & \\
\hline \multirow[t]{2}{*}{ Constant } & -0.51 & & -0.53 & & $-0.81^{\star}$ & & -0.12 & & $1.19^{\star \star \star}$ & \\
\hline & $(0.428)$ & & $(0.445)$ & & $(0.471)$ & & $(0.423)$ & & $(0.443)$ & \\
\hline$R^{2}$ & 0.081 & & 0.033 & & 0.019 & & 0.028 & & 0.116 & \\
\hline Average prediction & & 0.489 & & 0.328 & & 0.257 & & 0.366 & & 0.568 \\
\hline Observations & 4429 & & 4429 & & 4429 & & 4429 & & 4429 & \\
\hline
\end{tabular}

Note: Robust standard errors in parentheses.

${ }^{\star * *} p<0.01,{ }^{* *} p<0.05,{ }^{*} p<0.10$. 
As expected, support for the specific policy proposals is considerably lower than for support for federal action in the abstract (0.845). We find that support ranges from 0.257 for the arbitration proposal to 0.568 for the proposal focused on providing information to consumers. Although results are inconsistently significant when analyzing explanatory variables, the measures do work in the expected directions. Higher levels of education (significant 3 of 5 times), being a woman (3), and more comprehensive state protections (1) are positive predictors of policy support, while conservatism (2), better health (3), being uninsured (3), being on Medicare (3) and being on Medicaid (1) are negatively signed. We also find negative effects for being Black (2) and being Hispanic (2). Finally, we find no effect for any of our measures related to experiencing surprise bills.

To better discern general patterns of support for federal policy solutions to surprise billing, we created an additive index of the five policies and estimated both standard OLS and Poisson models, which are available in the Appendix in Tables A6 and A7. We further illustrate these findings in Figure A1, varying measures of interest from minimum to maximum values while holding other variables at their means. There we find that the average predictions amount to support for 2.7 of 5 proposals in all count models and that substantial differences in the frequency of support of federal policy proposals based on education, health, insurance status, age and race and ethnicity. Ultimately, the main drivers of support for more policy proposals appear to be poor health and old age, whereas opposition emerges based on insurance status, race and ethnicity.

\section{Discussion}

As the burden of surprise medical bills on Americans continues to grow, more research is needed to understand not only the scope of the problem, but also the impact of surprise bills on American consumers and their willingness to support federal policy change. Our study serves as a useful first step in that direction. Our results suggest that well over half of Americans have either experienced a surprise medical bill themselves or had a family member experience one. This past experience serves as an important predictor for subsequent knowledge, concern and support for federal policy action on surprise billing in the abstract. When studying public knowledge of the topic, our research demonstrates that just over two-thirds of Americans have heard of the problem, with knowledge highest among the educated and those who have previously experienced a surprise bill. Although the past experience finding is unsurprising, the education result is worth noting - less educated Americans, who may be less likely to have been exposed to news about surprise bills and less likely to understand the complexities of the American insurance system, are also less knowledgeable about surprise billing. This finding makes it likely that this financially vulnerable population might unknowingly face significant consequences when seeking medical care. Just as important, Hispanics and the uninsured are also less knowledgeable about surprise billing. This lack of knowledge puts these groups at an increased chance of being surprised by future medical bills and highlights the need to further educate the population on the problem to reduce these knowledge gaps.

Although understanding knowledge of surprise billing is valuable, from a policy perspective, levels of concern about surprise billing and support for policy change are perhaps even more important. Concerning the former, we find that a large number of Americans - roughly 7 in 10 - are somewhat or very concerned about the issue, with almost 4 in 10 falling into the latter category. Importantly, concern about future surprise bills may affect individuals' decisions to seek care, either delaying it or omitting it entirely (Chartock et al., 2019; Busch and Kyanko, 2020). This, of course, may come with significant health and financial repercussions down the road. Individuals who previously experienced a surprise medical bill may be particularly at risk.

Finally, our study indicates high levels of support in the American public for federal policymakers to intervene with the issue of surprise medical bills in the abstract. We find average predictions of support in excess of 0.900 for the most liberal respondents and 0.800 for conservative 
respondents, with all other variables held at their means. Even in times of partisan polarization, stopping surprise billing appears to be one unifying issue among Americans.

Notably, this abstract support dissipates once we asked about specific policy solutions, with only one of five proposals exhibiting an average prediction above 0.500 . Our findings for a cumulative index of support for the five proposals available in the Appendix offer more clarity. Sicker, older and more educated individuals support more federal proposals whereas minorities and those on public insurance coverage consistently support fewer proposals. In the case of surprise billing, confronted with public campaigns by interest groups pulling policymakers and the public in opposite directions, popular support does not necessarily translate into concrete support for specific policy actions.

Interestingly, although past bill experience is a consistent predictor of supporting the idea that the federal government should take some sort of action, its influence dissipates once focused on the nuances of specific policy proposals. This suggests that past experiences alone may not be enough to push individuals toward or against specific policy ideas, even as they won't change in the abstract. Exploring the interplay of past experiences and support for technical policy solutions warrants further exploration in future research. Furthermore, we surprisingly find that the policies already in place in some states to protect individuals against balance billing do not appear to influence knowledge of or concern about surprise bills. This finding suggests that individuals may not be well attuned to the actions already taken by states, and that future research should explore the extent to which the public is aware of the actions taken by states to protect their citizens from surprise medical bills. At the same time, it may also highlight the ineffectiveness of these protections which, as outlined above, do not apply to ERISA plans.

Our study is not without limitations. First, we administered our survey prior to the outbreak of the coronavirus pandemic in the United States. Although it is unclear what the health care system and health politics will look like in the aftermath, the pandemic pushed federal policymakers to implement changes to surprise billing protections to ensure that Americans were less likely bear the brunt of the outbreak's health costs. Notably, the Department of Health and Human Services included surprise billing protections in its recent stimulus funding agreements with individual providers (Haeder, 2020; Huetteman, 2020). It is also possible that the experience with the pandemic could change the outlook of Americans toward the topic, or health care more broadly (Haeder et al., 2021), with the pandemic increasing unemployment rates, the need for medical services and the percentage of Americans who are unable to afford even minor out of pocket costs. Of course, the timing of our survey before the pandemic and the passage of any federal legislation does have some benefits. It provides evidence of public attitudes before the pandemic and federal intervention, which will allow future researchers to compare attitudes before and after these important events.

Additionally, Americans' attitudes are subject to change as more states act independently of the federal government. As more states pursue comprehensive approaches to balance billing or other policies to help Americans combat surprise medical bills, attitudes could continue to change. Beyond these issues, our analysis is also limited by not asking how recently individuals received surprise medical bills and by measuring policy support using a binary yes/no scale. It is possible that more recent surprise bills are more influential on attitudes than older surprise bills and that we might find more variation in attitudes if more scale points were provided; however, our survey does not allow us to assess these possibilities.

Finally, there are some limitations related to our measures used in our analysis. Given our reliance on self-reports, it is possible that individuals could inaccurately attribute the type of insurance that they have. Relatedly, individual estimates of the size of the surprise bills received could be inaccurate, as most individuals will not have perfect recall of bill size. Finally, our survey was not designed to capture the type of insurance held by family members. To the extent that the type of insurance held by family members shapes a respondent's behavior, we are unable to capture that possibility. 


\section{Conclusions}

Our findings here resonate with the experience of many previous efforts to reform health care, both large- and small-scale. Unquestionably, the U.S. health care system is highly inequitable, and calls for changes are common. Many policy solutions have been brought forward, from allpayer systems to establishing consumer protections from surprise billing. Support in the abstract is often overwhelming. Yet, explaining intricate policy details to the public is challenging if not impossible and reform efforts quickly run into the wood chipper of interest group campaigns. Surprise billing reforms serve as the most recent example of these realities of the U.S. political system.

Critically, the lack of a strong partisan divide and high support for policy change across the political spectrum bolsters the possibility that surprise billing could be the rare policy topic where policy change became possible over the opposition of intense and well-financed interests even if it had to be achieved via an omnibus bill. Both Republicans and Democrats in the general public are highly supportive of policy change, reducing the possibility that politicians will be punished at the ballot box for taking action and making it much harder for oppositional groups to threaten electoral retribution. Yet even then, protections are incomplete, and implementation through the rulemaking process may further favor interest groups over consumers. Finally, the legality of federal action may still be contested through the court system. Thus, although the protections passed in the waning days of the Trump Administration are a step forward, further actions may be needed.

Conflict of interest. The authors have no known conflicts of interest related to this research.

\section{References}

Adler L, Hall M, Brandt C, Ginsburg PB, Lieberman S, DeVore S, Hempstead K, Sabatini N, Antos J and Haft H (2017) Stopping Surprise Medical Bills: Federal Action is Needed. Health Affairs Blog (blog). 1 February. Available at https://www. healthaffairs.org/do/10.1377/hblog20170201.058570/full/.

Adler L, Fiedler M, Ginsburg PB, Hall M, Trish E, Linke Young C and Duffy EL (2019) State Approaches to Mitigating Surprise Out-of-Network Billing. USC-Brookings Schaeffer Initiative for Health Policy, February.

Bartholomae S, Russell MB, Braun B and McCoy T (2016) Building health insurance literacy: evidence from the smart choice health insurance ${ }^{\mathrm{TM}}$ program. Journal of Family and Economic Issues 37, 140-155.

Bindman A (2018) Curbing surprise medical bills can be a window into cost control. Journal of the American Medical Association 320, 2065-2066.

Blumenthal D and Morone JA (2010) The Heart of Power: Health and Politics in the Oval Office. Berkeley: University of California Press.

Bluth R (2019) Congress Considers Bipartisan Compromise Legislation on Surprise Medical Bills. National Public Radio, 17 December 2019. Available at https://www.npr.org/sections/health-shots/2019/12/17/788624397/congress-considers-bipartisan-compromise-legislation-on-surprise-medical-bills.

Bluth R and Huetteman E (2019) Investors' Deep-Pocket Push to Defend Surprise Medical Bills. Kaiser Health News, 11 September 2019.

Boccuti C (2016) Paying a Visit to the Doctor: Current Financial Protections for Medicare Patients When Receiving Physician Services. Menlo Park, CA: Kaiser Family Foundation.

Brady DW and Kessler DP (2010a) Who supports health reform? PS: Political Science \& Politics 43, 1-6.

Brady DW and Kessler DP (2010b) Why is health reform so difficult? Journal of Health Politics, Policy and Law 35, 161-175.

Brown EJ, Polsky D, Barbu CM, Seymour JW and Grande D (2016) Racial disparities in geographic access to primary care in Philadelphia. Health Affairs 35, 1374-1381.

Brown ECF, Trish E, Ly B, Hall M and Adler L (2020) Out-of-network air ambulance bills: prevalence, magnitude, and policy solutions. Milbank Quarterly 98, 747-774.

Busch SH and Kyanko KA (2020) Incorrect provider directories associated with out-of-network mental health care and outpatient surprise bills: an examination of the role inaccurate provider directories play in out-of-network mental health treatment and surprise bills. Health Affairs 39, 975-983.

Callaghan T, Motta M, Sylvester S, Lunz Trujillo K and Blackburn CC (2019) Parent psychology and the decision to delay childhood vaccination. Social Science \& Medicine 238, 112407.

Cameron AC and Trivedi PK (2010) Microeconometrics Using Stata, Revised Edn. College Station, TX: Stata Press. 
Canes-Wrone B and Shotts KW (2004) The conditional nature of presidential responsiveness to public opinion. American Journal of Political Science 48, 690-706.

Chartock B, Garmon C and Schutz S (2019) Consumers' responses to surprise medical bills in elective situations. Health Affairs 38, 425-430.

Chhabra KR, McGuire K, Sheetz KH, Scott JW, Nuliyalu U and Ryan AM (2020a) Most patients undergoing ground and air ambulance transportation receive sizable out-of-network bills: an analysis of the prevalence and financial impact of out-of-network billing for ground and air ambulance transportation. Health Affairs 39, 777-790.

Chhabra KR, Sheetz KH, Nuliyalu U, Dekhne MS, Ryan AM and Dimick JB (2020b) Out-of-network bills for privately insured patients undergoing elective surgery with In-network primary surgeons and facilities. Journal of the American Medical Association 323, 538-547.

Claxton G, Rae M, Cox C and Levitt L (2019) An Analysis of Out-of-Network Claims in Large Employer Health Plans. Kaiser Family Foundation.

Cooper Z and Morton FS (2016) Out-of-network emergency-physician bills: an unwelcome surprise. New England Journal of Medicine 375, 1915-1918.

Cooper Z, Scott Morton F and Shekita N (2019) Surprise! Out-of-Network Billing for Emergency Care in the United States. Cambridge, MA: National Bureau of Economic Research.

Cooper Z, Nguyen H, Shekita N and Morton FS (2020) Out-of-network billing and negotiated payments for hospital-based physicians. Health Affairs 39, 24-32.

Coppock A and McClellan OA (2019) Validating the demographic, political, psychological, and experimental results obtained from a new source of online survey respondents. Research \& Politics 6, 1-14.

Cramer KJ (2016) The Politics of Resentment: Rural Consciousness in Wisconsin and the Rise of Scott Walke. Chicago, IL: University of Chicago Press.

Dekhne M, Adler L, Sheetz K and Chhabra K (2019) Federal Policy to End Surprise Billing: Building on Prior Approaches. Health Affairs Blog (blog). Health Affairs. 22 February.

Duffy EL, Adler L, Ginsburg PB and Trish E (2020) Prevalence and characteristics of surprise out-of-network bills from professionals in ambulatory surgery centers. Health Affairs 39, 783-790.

Evers-Hillstrom K (2019) Surprise Medical Bills Legislation Drives Spike in Q3 Lobbying Spending. Washington, DC: OpenSecrets.org.

Families USA (2019) Families USA Surprise Medical Bills Survey. Washington, DC: Families USA.

Federal Reserve System (2019) Report on the Economic Well-Being of U.S. Households in 2018. Washington, DC: Federal Reserve System.

Fenno R (2003) Home Style: House Members in Their Districts. New York, NY: Longman.

Feyman Y, Figueroa JF, Polsky DE, Adelberg M and Frakt A (2019) Primary care physician networks in Medicare advantage. Health Affairs 38, 537-544.

Fulton BD (2017) Health care market concentration trends in the United States: evidence and policy responses. Health Affairs 36, 1530-1538.

Gabel JR, Ginsburg PB, Whitmore HH and Pickreign JD (2000) Withering on the vine: the decline of indemnity health insurance. Health Affairs 19, 152-157.

Garmon C and Chartock B (2017) One in five inpatient emergency department cases may lead to surprise bills. Health Affairs 36, 177-181.

Gilens M (2009) Why Americans Hate Welfare: Race, Media, and the Politics of Antipoverty Policy. Chicago: University of Chicago Press.

Gold J 2019. 'First Kidney Failure, Then a \$540,842 Bill for Dialysis'. Kaiser Health News, 25 July 2019. Available at https:// khn.org/news/first-kidney-failure-then-a-540842-bill-for-dialysis/.

Gray BH (2006) The rise and decline of the HMO: A chapter in U.S. health-policy history. In Stevens RA, Rosenberg CE and Burns LR (eds), History and Health Policy in the United States: Putting the Past Back In. New Brunswick, NJ: Rutgers University Press, pp. 309-340.

Hacker JS (1997) The Road to Nowhere: The Genesis of President Clinton's Plan for Health Security. Princeton, N.J.: Princeton University Press.

Haeder SF (2014) Balancing adequacy and affordability?: Essential health benefits under the affordable care act. Health Policy 118, 285-291.

Haeder SF (2020) Inadequate in the best of times: reevaluating provider networks in light of the coronavirus pandemic. World Medical \& Health Policy 12, 282-290.

Haeder SF (2021) Joining the herd? U.S. public opinion and vaccination requirements across educational settings during the COVID-19 pandemic. Vaccine 39, 2375-2385.

Haeder SF and Yackee SW (2020a) A look under the hood: regulatory policymaking and the affordable care act. Journal of Health Politics, Policy and Law 45, 771-786.

Haeder SF and Yackee SW (2020b) Out of the public's eye? Lobbying the president's office of information and regulatory affairs. Interest Group \& Advocacy 9, 410-424. 
Haeder SF, Weimer DL and Mukamel DB (2015a) California hospital networks are narrower in marketplace than in commercial plans, but access and quality are similar. Health Affairs 34, 741-748.

Haeder SF, Weimer DL and Mukamel DB (2015b) Narrow networks and the affordable care act. Journal of the American Medical Association 314, 669-670.

Haeder SF, Weimer DL and Mukamel DB (2019a) A knotty problem: consumer access and the regulation of provider networks. Journal of Health Politics, Policy and Law 44, 937-954.

Haeder SF, Weimer DL and Mukamel DB (2019b) Surprise Billing: No Surprise in View of Network Complexity. Health Affairs Blog (blog), Health Affairs, 5 June. Available at https://www.healthaffairs.org/do/10.1377/hblog20190603.704918/ full/.

Haeder SF, Sylvester S and Callaghan TH (2021) Lingering legacies: public attitudes about Medicaid beneficiaries and work requirements. Journal of Health Politics, Policy and Law 46, 305-355.

Hawryluk M and O’Neill S (2019) Nothing to Sneeze at: \$2659 Bill to Pluck Doll's Shoe from Girl's Nose. National Public Radio, 26 November 2019. Available at https://www.npr.org/sections/health-shots/2019/11/26/782889808/nothing-tosneeze-at-2-659-bill-to-pluck-dolls-shoe-from-girl-s-nostril.

Ho V and Hamilton BH (2000) Hospital mergers and acquisitions: does market consolidation harm patients? Journal of Health Economics 19, 767-791. http://www.sciencedirect.com/science/article/pii/S0167629600000527.

Hoadley J, Fuchs BC and Lucia K (2019a) Update on Federal Surprise Billing Legislation: Understanding a Flurry of New Proposals. To the Point (blog), Commonwealth Fund. 20 February.

Hoadley J, Lucia K and Kona M (2019b) States are Taking New Steps to Protect Consumers from Balance Billing, But Federal Action is Necessary to Fill Gaps. To the Point (blog), Commonwealth Fund. 31 July.

Hoadley J, Fuchs BC and Lucia K (2020a) Update on Federal Surprise Billing Legislation: New Bills Contain Key Differences. To the Point (blog), Commonwealth Fund. 20 February.

Hoadley J, Keith K and Lucia K (2020b) Unpacking the No Surprises Act: An Opportunity to Protect Millions. Health Affairs Blog (blog). 1 May.

Hoadley J, Kona M and Lucia K (2020c) States Can Prevent Surprise Bills for Patients Seeking Coronavirus Care. To the Point (blog), Commonwealth Fund. 10 June.

Huetteman E (2020) In Fine Print, HHS Appears to Ban All Surprise Billing During the Pandemic. Kaiser Health News, 17 April 2020. Available at https://khn.org/news/in-fine-print-hhs-appears-to-ban-all-surprise-billing-during-the-pandemic/.

Jacobson G, Rae M, Neuman T, Orgera K and Boccuti C (2017) Medicare Advantage: How Robust are Plans' Physician Networks? Menlo Park, CA: Kaiser Family Foundation.

Kennedy K, Johnson W and Biniek JF (2019) Surprise Out-of-Network Medical Bills During In-Network Hospital Admissions Varied by State and Medical Specialty, 2016. Washington, DC: Health Care Cost Institute.

Kim J, Braun B and Williams AD (2013) Understanding health insurance literacy: a literature review. Family and Consumer Sciences Research Journal 42, 3-13.

Kirzinger A, Wu B, Munana C and Brodie M (2018) Kaiser Health Tracking Poll Late Summer 2018: The Election, Pre-Existing Conditions, and Surprises On Medical Bills. San Francisco, CA: Kaiser Family Foundation.

Kirzinger A, Kearney A and Brodie M (2019) KFF Health Tracking Poll - September 2019: Health Care Policy in Congress and on the Campaign Trail. San Francisco, CA: Kaiser Family Foundation.

Kliff S (2019) Surprise medical bills, the high cost of emergency department care, and the effects on patients. JAMA Internal Medicine 179, 1457-1458.

Kona M (2019) State Balance Billing Protections. Washington, DC: The Commonwealth Fund.

Krutz GS (2001) Hitching a Ride: Omnibus Legislating in the U.S. Congress. Columbus, OH: Ohio State University Press.

Loewenstein G, Friedman JY, McGill B, Ahmad S, Linck S, Sinkula S, Beshears J, Choi JJ, Kolstad J and Laibson D (2013) Consumers' misunderstanding of health insurance. Journal of Health Economics 32, 850-862.

Long S and Freese J (2014) Regression Models for Categorical Dependent Variables Using Stata, 3rd edn. College Station, TX: Stata Press.

Lucia K, Hoadley J and Williams A (2017) Balance Billing by Health Care Providers: Assessing Consumer Protections Across States. Washington, DC: Commonwealth Fund.

Lunz Trujillo K, Motta M, Callaghan T and Sylvester S (2020) Correcting misperceptions about the MMR vaccine: using psychological risk factors to inform targeted communication strategies. Political Research Quarterly 74, 464-478.

Matoff-Stepp S, Applebaum B, Pooler J and Kavanagh E (2014) Women as health care decision-makers: implications for health care coverage in the United States. Journal of Health Care for the Poor and Underserved 25, 1507-1513.

Mayhew DR (1974/2004) Congress: The Electoral Connection. New Haven, CT: Yale University Press.

Mayhew DR (2004) Congress: The Electoral Connection, 2nd edn. New Haven, CT: Yale University Press.

Motta M and Callaghan TH (2020) The pervasiveness and consequences of medical folk wisdom in the United States. Scientific Reports 10, 1-10.

Neyman J and Scott EL (1948) Consistent estimates based on partially consistent observations. Econometrica: Journal of the Econometric Society 16, 1-32.

Page BI and Shapiro RY (1983) Effects of public opinion on policy. American Political Science Review 77, 175-190. 
Polsky D, Cidav Z and Swanson A (2016) Marketplace plans with narrow physician networks feature lower monthly premiums than plans with larger networks. Health Affairs 35, 1842-1848.

Pradhan R (2020) Doctors Push Back as Congress Takes Aim at Surprise Medical Bills. NPR, 12 February 2020.

Pressman JL and Wildavsky A (1973) Implementation: How Great Expectations in Washington are Dashed in Oakland; Or, Why It's Amazing That Federal Programs Work at All, This Being a Saga of the Economic Development Administration as Told by Two Sympathetic Observers Who Seek to Build Morals on a Foundation of Ruined Hopes. Berkeley: University of California Press.

Rae M, Claxton G, Kurani N, McDermott D and Cox C (2020) Potential Costs of COVID-19 Treatment for People With Employer Coverage. San Francisco, CA: Kaiser Family Foundation.

Reinhardt UE (2019) Priced Out: The Economic and Ethical Costs of American Health Care. Princeton, NJ: Princeton University Press.

Riker WH (1986) The Art of Political Manipulation. New Haven, CT: Yale University Press.

Rodriguez C (2019) Summer Bummer: A Young Camper’s \$142,938 Snakebite. National Public Radio, 19 April 2019. Available at https://www.npr.org/sections/health-shots/2019/04/29/717467217/summer-bummer-a-young-campers-142938-snakebite.

Rosenthal E (2017) An American Sickness: How Healthcare Became Big Business and How You Can Take it Back. New York: Vol. Penguin Press.

Sanger-Katz M, Creswell J and Abelson R (2019) Mystery Solved: Private-Equity-Backed Firms are Behind Ad Blitz on 'Surprise Billing'. New York Times, 13 September 2019.

Schneider AL and Ingram H (1997) Policy Design for Democracy. Lawrence, KS: University of Kansas Press.

Scott D (2020) Congress Might Finally Have a Deal to Stop Surprise Medical Bills. Vox.com, 14 December 2020.

Short PF, Graefe DR and Schoen C 2003. Chrun, Churn, Churn: How Instability of Health Insurance Shapes America's Uninsured Problem. Washington, DC: Commonwealth Fun.

Starr P (2011) Remedy and Reaction: The Peculiar American Struggle Over Health Care Reform. New Haven, CT: Yale University Press.

Sun EC, Mello MM, Moshfegh J and Baker LC (2019) Assessment of out-of-network billing for privately insured patients receiving care in in-network hospitals. JAMA Internal Medicine 179, 1543-1550.

Tsebelis G (2002) Veto Players: How Political Institutions Work. Princeton, NJ: Princeton University Press.

U.S. Government Accountability Office (2019) Air Ambulance: Available Data Show Privately-Insured Patients Are at Financial Risk. Washington, DC: U.S. Government Accountability Office.

Vistnes JP, Rohde F, Miller GE and Cooper PF (2017) Substantial churn in health insurance offerings by small employers, 2014-15. Health Affairs 36, 1632-1636.

Wilson JQ (1973) Political Organizations. New York: Basic Books, Inc.

Wood T and Porter E (2019) The elusive backfire effect: mass attitudes' steadfast factual adherence. Political Behavior 41, 135-163.

Young CL, Fiedler M, Adler L and Lee S (2019) What is Surprise Billing for Medical Care? Washington, DC: Brookings Institution. 


\section{Appendix A}

Table A1. Comparison of sample characteristics to national benchmarks

\begin{tabular}{lrrrr}
\hline Variable & Raw results & Weighted results & Benchmark & Benchmark source \\
\hline Female & $55 \%$ & $52 \%$ & $51 \%$ & CPS 2018 \\
\hline College degree & $44 \%$ & $35 \%$ & $31 \%$ & CPS 2018 \\
\hline Black & $13 \%$ & $14 \%$ & $13 \%$ & CPS 2018 \\
\hline White & $70 \%$ & $64 \%$ & $62 \%$ & CPS 2018 \\
\hline Hispanic & $11 \%$ & $17 \%$ & $18 \%$ & CPS 2018 \\
\hline Mean age & 46 & 47 & 47 & ANES (Wgt.) \\
\hline Median income & $\$ 35-39,000$ & $\$ 55-59,999$ & $\$ 55-59,999$ & ANES (Wgt.) \\
\hline
\end{tabular}

Source: Results taken from authors' analysis of original opinion dataset. Benchmarks come from the 2018 Census Current Population Survey and the 2016 American National Election Survey.

Notes: These results compare our data to known population benchmarks while accounting for post-stratification weights that adjust for gender, education, race, age and income. We rely on the CPS as a benchmark where possible but switch to the American National Election Study in cases where it is not possible to use the CPS or where categories better align with the ANES. 
Table A2. Support for specific policies - family experience

\begin{tabular}{|c|c|c|c|c|c|}
\hline & $(1)$ & $(2)$ & (3) & (4) & (5) \\
\hline Variables & $\begin{array}{l}\text { In-network } \\
\text { facilities }\end{array}$ & $\begin{array}{l}\text { Reference } \\
\text { pricing }\end{array}$ & Arbitration & $\begin{array}{l}\text { Broader } \\
\text { networks }\end{array}$ & $\begin{array}{l}\text { Inform } \\
\text { patients }\end{array}$ \\
\hline \multirow[t]{2}{*}{ Family surprise bill } & 0.16 & -0.06 & 0.06 & $0.17^{\star}$ & -0.09 \\
\hline & $(0.102)$ & $(0.106)$ & $(0.115)$ & $(0.103)$ & $(0.100)$ \\
\hline \multirow[t]{2}{*}{ Medicare } & $-0.24^{\star \star}$ & 0.15 & -0.11 & $-0.21^{*}$ & $-0.28^{\star \star}$ \\
\hline & $(0.121)$ & $(0.126)$ & $(0.135)$ & $(0.120)$ & $(0.129)$ \\
\hline \multirow[t]{2}{*}{ Medicaid } & $-0.33^{\star \star}$ & -0.10 & 0.01 & -0.19 & -0.18 \\
\hline & $(0.130)$ & $(0.131)$ & $(0.150)$ & $(0.129)$ & $(0.130)$ \\
\hline \multirow[t]{2}{*}{ Uninsured } & $-0.31^{\star \star}$ & -0.13 & -0.12 & $-0.29^{\star \star}$ & $-0.32^{\star \star \star}$ \\
\hline & $(0.123)$ & $(0.126)$ & $(0.138)$ & $(0.124)$ & $(0.120)$ \\
\hline \multirow[t]{2}{*}{ Overall health } & $-0.12^{\star \star \star}$ & -0.07 & -0.03 & $-0.18^{\star \star \star}$ & $-0.14^{\star \star \star}$ \\
\hline & $(0.042)$ & $(0.044)$ & $(0.048)$ & $(0.042)$ & $(0.043)$ \\
\hline \multirow[t]{2}{*}{ Education } & $0.09^{*}$ & $0.16^{\star \star \star}$ & -0.03 & 0.07 & $0.10^{\star}$ \\
\hline & $(0.051)$ & $(0.056)$ & $(0.061)$ & $(0.052)$ & $(0.052)$ \\
\hline \multirow[t]{2}{*}{ Female } & $0.22^{\star \star \star}$ & -0.10 & -0.13 & $0.23^{\star \star \star}$ & $0.24^{\star \star \star}$ \\
\hline & $(0.083)$ & $(0.086)$ & $(0.094)$ & $(0.083)$ & $(0.085)$ \\
\hline \multirow[t]{2}{*}{ Household income } & 0.00 & -0.00 & $0.02^{\star \star}$ & -0.01 & 0.01 \\
\hline & $(0.007)$ & $(0.007)$ & $(0.008)$ & $(0.007)$ & $(0.008)$ \\
\hline \multirow[t]{2}{*}{ Party identification } & -0.02 & $-0.07^{\star \star \star}$ & -0.03 & $-0.04^{\star \star}$ & -0.00 \\
\hline & $(0.019)$ & $(0.020)$ & $(0.021)$ & $(0.019)$ & $(0.019)$ \\
\hline \multirow[t]{2}{*}{ Age } & 0.00 & -0.02 & -0.01 & 0.01 & $-0.06^{\star \star \star}$ \\
\hline & $(0.016)$ & $(0.016)$ & $(0.017)$ & $(0.015)$ & $(0.017)$ \\
\hline \multirow[t]{2}{*}{ Age squared } & 0.00 & 0.00 & 0.00 & -0.00 & $0.00^{\star \star \star}$ \\
\hline & $(0.000)$ & $(0.000)$ & $(0.000)$ & $(0.000)$ & $(0.000)$ \\
\hline \multirow[t]{2}{*}{ Black } & $-0.24^{\star}$ & -0.12 & -0.02 & -0.11 & $-0.33^{\star \star \star}$ \\
\hline & $(0.128)$ & $(0.135)$ & $(0.144)$ & $(0.127)$ & $(0.123)$ \\
\hline \multirow[t]{2}{*}{ Hispanic } & -0.19 & -0.02 & $-0.37^{\star \star}$ & $-0.24^{\star}$ & $-0.46^{\star \star \star}$ \\
\hline & $(0.130)$ & $(0.136)$ & $(0.155)$ & $(0.134)$ & $(0.129)$ \\
\hline \multirow{2}{*}{$\begin{array}{l}\text { Balance bill } \\
\text { protections }\end{array}$} & $0.10^{\star \star}$ & 0.03 & 0.06 & -0.05 & 0.01 \\
\hline & $(0.049)$ & $(0.050)$ & $(0.056)$ & $(0.049)$ & $(0.050)$ \\
\hline \multirow[t]{2}{*}{ Constant } & -0.54 & -0.51 & $-0.81^{\star}$ & -0.17 & $1.18^{\star \star \star}$ \\
\hline & $(0.428)$ & $(0.444)$ & $(0.471)$ & $(0.425)$ & $(0.443)$ \\
\hline Observations & 4445 & 4445 & 4445 & 4445 & 4445 \\
\hline
\end{tabular}

Note: Robust standard errors in parentheses. ${ }^{\star \star \star} p<0.01,{ }^{\star \star} p<0.05,{ }^{\star} p<0.10$. 
Table A3. Support for specific policies - personal and family surprise bill

\begin{tabular}{|c|c|c|c|c|c|}
\hline & (1) & $(2)$ & (3) & (4) & (5) \\
\hline Variables & $\begin{array}{l}\text { In-network } \\
\text { facilities }\end{array}$ & $\begin{array}{l}\text { Reference } \\
\text { pricing }\end{array}$ & Arbitration & $\begin{array}{l}\text { Broader } \\
\text { networks }\end{array}$ & $\begin{array}{l}\text { Inform } \\
\text { patients }\end{array}$ \\
\hline \multirow{2}{*}{$\begin{array}{l}\text { Both personal and family } \\
\text { surprise bill }\end{array}$} & 0.02 & $0.34^{\star \star}$ & -0.00 & -0.05 & -0.09 \\
\hline & $(0.151)$ & $(0.158)$ & $(0.172)$ & (0.149) & $(0.153)$ \\
\hline \multirow[t]{2}{*}{ Medicare } & $-0.24^{\star \star}$ & 0.14 & -0.11 & $-0.21^{\star}$ & $-0.28^{\star \star}$ \\
\hline & $(0.121)$ & $(0.126)$ & $(0.135)$ & $(0.121)$ & $(0.129)$ \\
\hline \multirow[t]{2}{*}{ Medicaid } & $-0.32^{\star \star}$ & -0.10 & 0.02 & -0.19 & -0.18 \\
\hline & $(0.130)$ & $(0.132)$ & $(0.150)$ & $(0.128)$ & $(0.130)$ \\
\hline \multirow[t]{2}{*}{ Uninsured } & $-0.31^{\star \star}$ & -0.12 & -0.12 & $-0.29^{\star \star}$ & $-0.32^{\star \star \star}$ \\
\hline & $(0.122)$ & $(0.125)$ & $(0.138)$ & $(0.123)$ & $(0.120)$ \\
\hline \multirow[t]{2}{*}{ Overall health } & $-0.11^{\star \star \star}$ & -0.07 & -0.03 & $-0.18^{\star \star \star}$ & $-0.14^{\star \star \star}$ \\
\hline & $(0.042)$ & $(0.044)$ & $(0.048)$ & $(0.042)$ & $(0.043)$ \\
\hline \multirow[t]{2}{*}{ Education } & $0.09^{\star}$ & $0.17^{\star \star \star}$ & -0.03 & 0.07 & $0.10^{*}$ \\
\hline & $(0.051)$ & $(0.056)$ & $(0.061)$ & $(0.052)$ & $(0.053)$ \\
\hline \multirow[t]{2}{*}{ Female } & $0.22^{\star \star \star}$ & -0.11 & -0.13 & $0.23^{\star \star \star}$ & $0.24^{\star \star \star}$ \\
\hline & $(0.083)$ & $(0.086)$ & $(0.094)$ & $(0.083)$ & $(0.085)$ \\
\hline \multirow[t]{2}{*}{ Household income } & 0.00 & -0.00 & $0.02^{\star \star}$ & -0.01 & 0.01 \\
\hline & $(0.007)$ & $(0.007)$ & $(0.008)$ & $(0.007)$ & $(0.008)$ \\
\hline \multirow[t]{2}{*}{ Party identification } & -0.02 & $-0.07^{\star \star \star}$ & -0.03 & $-0.04^{\star \star}$ & -0.00 \\
\hline & $(0.019)$ & $(0.020)$ & $(0.021)$ & $(0.019)$ & $(0.019)$ \\
\hline \multirow[t]{2}{*}{ Age } & 0.00 & -0.02 & -0.01 & 0.01 & $-0.06^{\star \star *}$ \\
\hline & $(0.016)$ & $(0.016)$ & $(0.017)$ & $(0.015)$ & $(0.017)$ \\
\hline \multirow[t]{2}{*}{ Age squared } & 0.00 & 0.00 & 0.00 & -0.00 & $0.00^{\star \star \star}$ \\
\hline & $(0.000)$ & $(0.000)$ & $(0.000)$ & $(0.000)$ & $(0.000)$ \\
\hline \multirow[t]{2}{*}{ Black } & $-0.24^{\star}$ & -0.13 & -0.02 & -0.11 & $-0.33^{\star \star \star}$ \\
\hline & $(0.128)$ & $(0.135)$ & $(0.144)$ & $(0.127)$ & $(0.123)$ \\
\hline \multirow[t]{2}{*}{ Hispanic } & -0.19 & -0.01 & $-0.37^{\star \star}$ & $-0.24^{\star}$ & $-0.46^{\star \star \star}$ \\
\hline & $(0.130)$ & $(0.136)$ & $(0.155)$ & $(0.134)$ & $(0.129)$ \\
\hline \multirow[t]{2}{*}{ Balance bill protections } & $0.10^{\star \star}$ & 0.03 & 0.06 & -0.05 & 0.01 \\
\hline & $(0.049)$ & $(0.050)$ & $(0.056)$ & $(0.049)$ & $(0.050)$ \\
\hline \multirow[t]{2}{*}{ Constant } & -0.50 & -0.56 & $-0.80^{\star}$ & -0.12 & $1.17^{\star \star \star}$ \\
\hline & $(0.427)$ & $(0.440)$ & $(0.470)$ & $(0.423)$ & $(0.442)$ \\
\hline Observations & 4445 & 4445 & 4445 & 4445 & 4445 \\
\hline
\end{tabular}

Note: Robust standard errors in parentheses.

${ }^{\star \star \star} p<0.01,{ }^{\star \star} p<0.05,{ }^{\star} p<0.10$. 
Table A4. Support for specific policies - any surprise bill

\begin{tabular}{|c|c|c|c|c|c|}
\hline & $(1)$ & $(2)$ & (3) & (4) & (5) \\
\hline Variables & $\begin{array}{l}\text { In-network } \\
\text { facilities }\end{array}$ & $\begin{array}{l}\text { Reference } \\
\text { pricing }\end{array}$ & Arbitration & $\begin{array}{l}\text { Broader } \\
\text { networks }\end{array}$ & $\begin{array}{l}\text { Inform } \\
\text { patients }\end{array}$ \\
\hline \multirow[t]{2}{*}{ Any surprise bill } & 0.05 & 0.09 & 0.09 & $0.18^{\star \star}$ & $-0.22^{\star \star}$ \\
\hline & $(0.085)$ & (0.089) & $(0.095)$ & $(0.086)$ & $(0.087)$ \\
\hline \multirow[t]{2}{*}{ Medicare } & $-0.25^{\star \star}$ & 0.14 & -0.11 & $-0.21^{*}$ & $-0.29^{\star \star}$ \\
\hline & $(0.121)$ & $(0.126)$ & $(0.136)$ & $(0.121)$ & $(0.129)$ \\
\hline \multirow[t]{2}{*}{ Medicaid } & $-0.33^{\star \star}$ & -0.10 & 0.01 & -0.19 & -0.18 \\
\hline & $(0.130)$ & $(0.132)$ & $(0.150)$ & $(0.129)$ & $(0.130)$ \\
\hline \multirow[t]{2}{*}{ Uninsured } & $-0.33^{\star \star \star}$ & -0.14 & -0.13 & $-0.29^{\star \star}$ & $-0.33^{\star \star \star}$ \\
\hline & $(0.123)$ & $(0.126)$ & $(0.138)$ & $(0.124)$ & $(0.122)$ \\
\hline \multirow[t]{2}{*}{ Overall health } & $-0.11^{\star \star}$ & -0.06 & -0.02 & $-0.18^{\star \star \star}$ & $-0.14^{\star \star \star}$ \\
\hline & $(0.042)$ & $(0.043)$ & $(0.048)$ & $(0.042)$ & $(0.043)$ \\
\hline \multirow[t]{2}{*}{ Education } & 0.08 & $0.17^{\star \star \star}$ & -0.03 & 0.07 & $0.11^{\star \star}$ \\
\hline & $(0.052)$ & $(0.057)$ & $(0.062)$ & $(0.052)$ & $(0.053)$ \\
\hline \multirow[t]{2}{*}{ Female } & $0.22^{\star \star \star}$ & -0.10 & -0.14 & $0.23^{\star \star \star}$ & $0.23^{\star \star \star}$ \\
\hline & $(0.083)$ & $(0.086)$ & $(0.094)$ & $(0.083)$ & $(0.085)$ \\
\hline \multirow[t]{2}{*}{ Household income } & 0.00 & -0.00 & $0.02^{\star \star}$ & -0.01 & 0.01 \\
\hline & $(0.007)$ & $(0.007)$ & $(0.008)$ & $(0.007)$ & $(0.008)$ \\
\hline \multirow[t]{2}{*}{ Party identification } & -0.02 & $-0.07^{\star \star \star}$ & -0.03 & $-0.04^{\star \star}$ & -0.00 \\
\hline & $(0.019)$ & $(0.020)$ & $(0.021)$ & $(0.019)$ & $(0.019)$ \\
\hline \multirow[t]{2}{*}{ Age } & 0.00 & -0.02 & -0.01 & 0.01 & $-0.06^{\star \star *}$ \\
\hline & $(0.016)$ & $(0.016)$ & $(0.017)$ & $(0.015)$ & $(0.017)$ \\
\hline \multirow[t]{2}{*}{ Age squared } & 0.00 & 0.00 & 0.00 & -0.00 & $0.00^{\star \star \star}$ \\
\hline & $(0.000)$ & $(0.000)$ & $(0.000)$ & $(0.000)$ & $(0.000)$ \\
\hline \multirow[t]{2}{*}{ Black } & $-0.27^{\star \star}$ & -0.12 & -0.02 & -0.11 & $-0.32^{\star \star \star}$ \\
\hline & $(0.129)$ & $(0.136)$ & $(0.144)$ & $(0.127)$ & $(0.125)$ \\
\hline \multirow[t]{2}{*}{ Hispanic } & -0.19 & -0.03 & $-0.38^{\star \star}$ & $-0.24^{\star}$ & $-0.46^{\star \star \star}$ \\
\hline & $(0.131)$ & $(0.136)$ & $(0.155)$ & $(0.134)$ & $(0.130)$ \\
\hline \multirow{2}{*}{$\begin{array}{l}\text { Balance bill } \\
\text { protections }\end{array}$} & $0.10^{\star \star}$ & 0.03 & 0.07 & -0.04 & 0.01 \\
\hline & $(0.049)$ & $(0.050)$ & $(0.056)$ & $(0.049)$ & $(0.050)$ \\
\hline \multirow[t]{2}{*}{ Constant } & -0.55 & -0.58 & $-0.85^{\star}$ & -0.20 & $1.29^{\star \star \star}$ \\
\hline & $(0.429)$ & $(0.446)$ & $(0.472)$ & $(0.427)$ & $(0.449)$ \\
\hline Observations & 4429 & 4429 & 4429 & 4429 & 4429 \\
\hline
\end{tabular}

Note: Robust standard errors in parentheses. ${ }^{\star \star \star} p<0.01,{ }^{\star \star} p<0.05,{ }^{\star} p<0.10$. 
Table A5. Support for specific policies - bill size

\begin{tabular}{|c|c|c|c|c|c|}
\hline & (1) & $(2)$ & (3) & (4) & (5) \\
\hline Variables & $\begin{array}{l}\text { In-network } \\
\text { facilities }\end{array}$ & $\begin{array}{l}\text { Reference } \\
\text { pricing }\end{array}$ & Arbitration & $\begin{array}{l}\text { Broader } \\
\text { networks }\end{array}$ & $\begin{array}{l}\text { Inform } \\
\text { patients }\end{array}$ \\
\hline \multirow[t]{2}{*}{ Large surprise bill } & -0.00 & 0.04 & 0.03 & 0.10 & 0.08 \\
\hline & $(0.108)$ & $(0.110)$ & $(0.120)$ & $(0.106)$ & $(0.113)$ \\
\hline \multirow[t]{2}{*}{ Medicare } & $-0.24^{\star \star}$ & 0.15 & -0.11 & $-0.20^{\star}$ & $-0.28^{\star \star}$ \\
\hline & $(0.121)$ & $(0.126)$ & $(0.135)$ & $(0.121)$ & $(0.129)$ \\
\hline \multirow[t]{2}{*}{ Medicaid } & $-0.32^{\star \star}$ & -0.10 & 0.02 & -0.18 & -0.17 \\
\hline & $(0.130)$ & $(0.131)$ & $(0.150)$ & $(0.129)$ & $(0.130)$ \\
\hline \multirow[t]{2}{*}{ Uninsured } & $-0.31^{\star \star}$ & -0.13 & -0.12 & $-0.28^{\star \star}$ & $-0.32^{\star \star \star}$ \\
\hline & $(0.123)$ & $(0.126)$ & $(0.139)$ & $(0.124)$ & $(0.120)$ \\
\hline \multirow[t]{2}{*}{ Overall health } & $-0.11^{\star \star \star}$ & -0.07 & -0.03 & $-0.18^{\star \star \star}$ & $-0.14^{\star \star \star}$ \\
\hline & $(0.042)$ & $(0.044)$ & $(0.048)$ & $(0.042)$ & $(0.043)$ \\
\hline \multirow[t]{2}{*}{ Education } & $0.09^{\star}$ & $0.16^{\star \star \star}$ & -0.03 & 0.07 & $0.10^{\star}$ \\
\hline & $(0.051)$ & $(0.056)$ & $(0.061)$ & $(0.052)$ & $(0.053)$ \\
\hline \multirow[t]{2}{*}{ Female } & $0.22^{\star \star \star}$ & -0.10 & -0.13 & $0.24^{\star * *}$ & $0.24^{\star \star \star}$ \\
\hline & $(0.083)$ & $(0.086)$ & $(0.094)$ & $(0.083)$ & $(0.085)$ \\
\hline \multirow[t]{2}{*}{ Household income } & 0.00 & -0.00 & $0.02^{\star \star}$ & -0.01 & 0.01 \\
\hline & $(0.007)$ & $(0.007)$ & $(0.008)$ & $(0.007)$ & $(0.008)$ \\
\hline \multirow[t]{2}{*}{ Party identification } & -0.02 & $-0.07^{\star \star \star}$ & -0.03 & $-0.04^{\star \star}$ & -0.00 \\
\hline & $(0.019)$ & $(0.020)$ & $(0.021)$ & $(0.019)$ & $(0.019)$ \\
\hline \multirow[t]{2}{*}{ Age } & 0.00 & -0.02 & -0.01 & 0.01 & $-0.06^{\star \star \star}$ \\
\hline & $(0.016)$ & $(0.016)$ & $(0.017)$ & $(0.015)$ & $(0.017)$ \\
\hline \multirow[t]{2}{*}{ Age squared } & 0.00 & 0.00 & 0.00 & -0.00 & $0.00^{\star \star \star}$ \\
\hline & $(0.000)$ & $(0.000)$ & $(0.000)$ & $(0.000)$ & $(0.000)$ \\
\hline \multirow[t]{2}{*}{ Black } & $-0.24^{\star}$ & -0.12 & -0.02 & -0.11 & $-0.33^{\star \star \star}$ \\
\hline & $(0.128)$ & $(0.135)$ & $(0.144)$ & $(0.127)$ & $(0.123)$ \\
\hline \multirow[t]{2}{*}{ Hispanic } & -0.19 & -0.02 & $-0.37^{\star \star}$ & $-0.24^{\star}$ & $-0.46^{\star \star \star}$ \\
\hline & $(0.130)$ & $(0.136)$ & $(0.155)$ & $(0.134)$ & $(0.129)$ \\
\hline \multirow{2}{*}{$\begin{array}{l}\text { Balance bill } \\
\text { protections }\end{array}$} & $0.10^{\star *}$ & 0.03 & 0.06 & -0.05 & 0.01 \\
\hline & $(0.049)$ & $(0.050)$ & $(0.056)$ & $(0.049)$ & $(0.050)$ \\
\hline \multirow[t]{2}{*}{ Constant } & -0.50 & -0.53 & $-0.80^{\star}$ & -0.14 & $1.15^{\star \star \star}$ \\
\hline & $(0.427)$ & $(0.444)$ & $(0.469)$ & $(0.423)$ & $(0.441)$ \\
\hline Observations & 4445 & 4445 & 4445 & 4445 & 4445 \\
\hline
\end{tabular}

Note: Robust standard errors in parentheses.

${ }^{\star \star \star} p<0.01,{ }^{\star \star} p<0.05,{ }^{\star} p<0.10$. 
Table A6. Number of policies supported to mitigate surprise billing: OLS

\begin{tabular}{|c|c|c|c|c|c|}
\hline & $(1)$ & $(2)$ & (3) & (4) & (5) \\
\hline Variables & Self & Family & Both & Any & Size \\
\hline \multirow[t]{2}{*}{ Personal surprise bill } & -0.01 & & & & \\
\hline & $(0.078)$ & & & & \\
\hline \multirow[t]{2}{*}{ Family surprise bill } & & 0.01 & & & \\
\hline & & $(0.091)$ & & & \\
\hline \multirow[t]{2}{*}{ Both personal and family surprise bill } & & & 0.05 & & \\
\hline & & & $(0.127)$ & & \\
\hline \multirow[t]{2}{*}{ Any surprise bill } & & & & 0.01 & \\
\hline & & & & $(0.072)$ & \\
\hline \multirow[t]{2}{*}{ Large surprise bill } & & & & & 0.08 \\
\hline & & & & & $(0.097)$ \\
\hline \multirow[t]{2}{*}{ Medicare } & $0.14^{\star \star \star}$ & $0.14^{\star \star \star}$ & $0.14^{\star \star \star}$ & $0.14^{\star \star \star}$ & $0.14^{\star \star \star}$ \\
\hline & $(0.045)$ & $(0.045)$ & $(0.046)$ & $(0.045)$ & $(0.045)$ \\
\hline \multirow[t]{2}{*}{ Medicaid } & 0.10 & 0.11 & 0.11 & 0.10 & 0.11 \\
\hline & $(0.072)$ & $(0.072)$ & $(0.072)$ & $(0.072)$ & $(0.072)$ \\
\hline \multirow[t]{2}{*}{ Uninsured } & 0.00 & 0.01 & 0.01 & 0.00 & 0.01 \\
\hline & $(0.006)$ & $(0.006)$ & $(0.006)$ & $(0.006)$ & $(0.006)$ \\
\hline \multirow[t]{2}{*}{ Overall health } & $-0.03^{\star}$ & $-0.03^{\star}$ & $-0.03^{\star}$ & $-0.03^{\star}$ & $-0.03^{\star}$ \\
\hline & $(0.016)$ & $(0.016)$ & $(0.016)$ & $(0.016)$ & $(0.016)$ \\
\hline \multirow[t]{2}{*}{ Education } & $-0.02^{\star}$ & -0.02 & $-0.02^{\star}$ & $-0.02^{\star}$ & $-0.02^{\star}$ \\
\hline & $(0.012)$ & $(0.012)$ & $(0.012)$ & $(0.012)$ & $(0.012)$ \\
\hline \multirow[t]{2}{*}{ Female } & $0.00^{\star \star \star}$ & $0.00^{\star \star \star}$ & $0.00^{\star \star \star}$ & $0.00^{\star \star \star}$ & $0.00^{\star \star \star}$ \\
\hline & $(0.000)$ & $(0.000)$ & $(0.000)$ & $(0.000)$ & $(0.000)$ \\
\hline \multirow[t]{2}{*}{ Household income } & $-0.19^{\star}$ & $-0.19^{\star}$ & $-0.20^{\star}$ & $-0.19^{\star}$ & $-0.19^{\star}$ \\
\hline & $(0.104)$ & $(0.103)$ & $(0.103)$ & $(0.104)$ & $(0.103)$ \\
\hline \multirow[t]{2}{*}{ Party identification } & $-0.35^{\star \star \star}$ & $-0.35^{\star \star \star}$ & $-0.35^{\star \star \star}$ & $-0.35^{\star \star \star}$ & $-0.35^{\star \star *}$ \\
\hline & $(0.102)$ & $(0.102)$ & $(0.102)$ & $(0.102)$ & $(0.101)$ \\
\hline \multirow[t]{2}{*}{ Age } & $-0.16^{\star \star \star}$ & $-0.17^{\star \star \star}$ & $-0.17^{\star \star \star}$ & $-0.16^{\star \star \star}$ & $-0.16^{\star \star \star}$ \\
\hline & $(0.036)$ & $(0.037)$ & $(0.037)$ & $(0.037)$ & $(0.037)$ \\
\hline \multirow[t]{2}{*}{ Age squared } & $-0.33^{\star \star \star}$ & $-0.31^{\star \star \star}$ & $-0.31^{\star \star \star}$ & $-0.33^{\star \star \star}$ & $-0.31^{\star \star \star}$ \\
\hline & $(0.101)$ & $(0.102)$ & $(0.102)$ & $(0.101)$ & $(0.102)$ \\
\hline \multirow[t]{2}{*}{ Black } & $-0.21^{\star \star}$ & $-0.20^{\star \star}$ & $-0.20^{\star \star}$ & $-0.21^{\star \star}$ & $-0.20^{\star}$ \\
\hline & $(0.102)$ & $(0.101)$ & $(0.102)$ & $(0.102)$ & $(0.102)$ \\
\hline \multirow[t]{2}{*}{ Hispanic } & $-0.25^{\star \star}$ & $-0.25^{\star \star}$ & $-0.25^{\star \star}$ & $-0.25^{\star \star}$ & $-0.24^{\star \star}$ \\
\hline & $(0.109)$ & $(0.109)$ & $(0.108)$ & $(0.109)$ & $(0.109)$ \\
\hline Balance bill protections & 0.05 & 0.04 & 0.04 & 0.05 & 0.04 \\
\hline
\end{tabular}


Table A6. (Continued.)

\begin{tabular}{|c|c|c|c|c|c|}
\hline & (1) & $(2)$ & (3) & (4) & (5) \\
\hline \multirow[t]{2}{*}{ Variables } & Self & Family & Both & Any & Size \\
\hline & $(0.042)$ & $(0.042)$ & $(0.042)$ & $(0.042)$ & $(0.042)$ \\
\hline \multirow[t]{2}{*}{ Constant } & $2.98^{\star \star \star}$ & $2.98^{\star \star \star}$ & $2.98^{\star \star \star}$ & $2.97^{\star \star \star}$ & $2.97^{\star \star \star}$ \\
\hline & $(0.349)$ & $(0.352)$ & $(0.350)$ & $(0.351)$ & $(0.348)$ \\
\hline Observations & 4429 & 4445 & 4445 & 4429 & 4445 \\
\hline$R^{2}$ & 0.08 & 0.08 & 0.08 & 0.08 & 0.08 \\
\hline
\end{tabular}

Note: Robust standard errors in parentheses.

${ }^{\star * \star} p<0.01,{ }^{* \star} p<0.05,{ }^{*} p<0.10$.

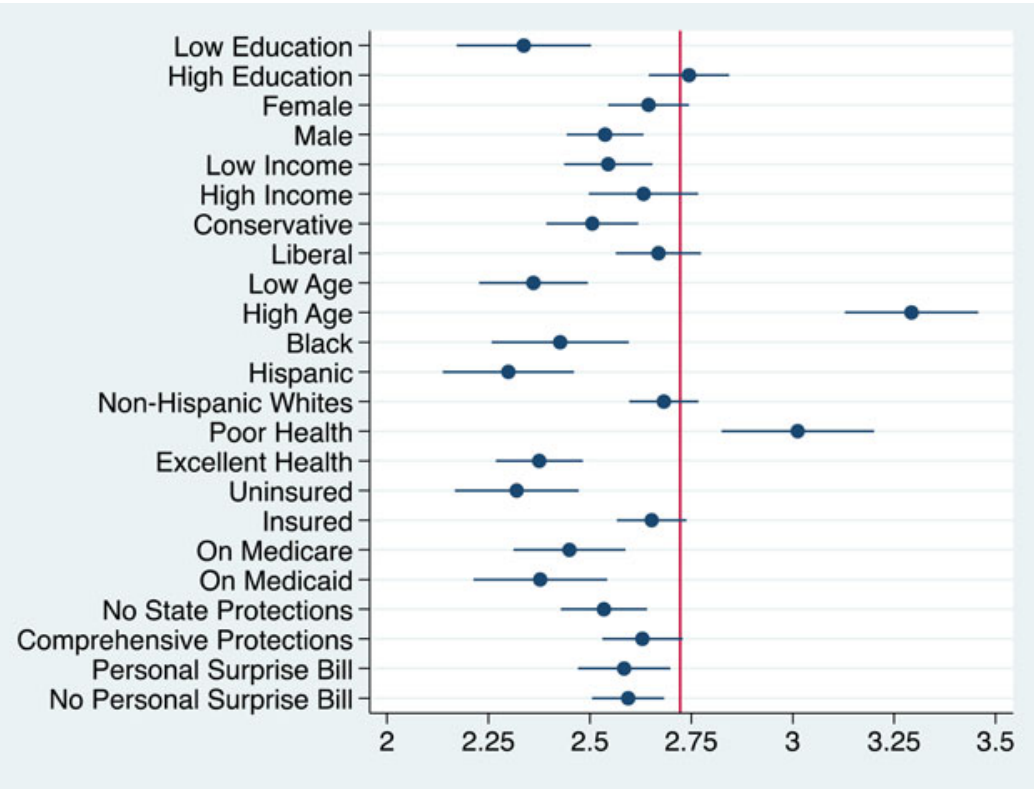

Figure A1. Predicted counts for support for five policies to mitigate surprise billing.

Notes: Estimate presented with $90 \%$ confidence bounds. Estimates based on results from model 15 . The vertical red line indicates the average prediction for model 15 . 
Table A7. Number of policies supported to mitigate surprise billing: Poisson

\begin{tabular}{|c|c|c|c|c|c|}
\hline & $(1)$ & $(2)$ & (3) & (4) & (5) \\
\hline Variables & Self & Family & Both & Any & Size \\
\hline \multirow[t]{2}{*}{ Personal surprise bill } & -0.00 & & & & \\
\hline & $(0.029)$ & & & & \\
\hline \multirow[t]{2}{*}{ Family surprise bill } & & 0.00 & & & \\
\hline & & $(0.034)$ & & & \\
\hline \multirow[t]{2}{*}{ Both personal and family surprise bill } & & & 0.02 & & \\
\hline & & & $(0.048)$ & & \\
\hline \multirow[t]{2}{*}{ Any surprise bill } & & & & 0.00 & \\
\hline & & & & $(0.026)$ & \\
\hline \multirow[t]{2}{*}{ Large surprise bill } & & & & & 0.03 \\
\hline & & & & & $(0.035)$ \\
\hline \multirow[t]{2}{*}{ Medicare } & $0.05^{\star \star \star}$ & $0.05^{\star \star \star}$ & $0.05^{\star \star \star}$ & $0.05^{\star \star \star}$ & $0.05^{\star \star \star}$ \\
\hline & $(0.017)$ & $(0.017)$ & $(0.017)$ & $(0.017)$ & $(0.017)$ \\
\hline \multirow[t]{2}{*}{ Medicaid } & 0.04 & $0.04^{\star}$ & $0.04^{\star}$ & 0.04 & $0.04^{\star}$ \\
\hline & $(0.026)$ & $(0.026)$ & $(0.026)$ & $(0.026)$ & $(0.026)$ \\
\hline \multirow[t]{2}{*}{ Uninsured } & 0.00 & 0.00 & 0.00 & 0.00 & 0.00 \\
\hline & $(0.002)$ & $(0.002)$ & $(0.002)$ & $(0.002)$ & $(0.002)$ \\
\hline \multirow[t]{2}{*}{ Overall health } & $-0.01^{*}$ & $-0.01^{\star}$ & $-0.01^{\star}$ & $-0.01^{*}$ & $-0.01^{*}$ \\
\hline & $(0.006)$ & $(0.006)$ & $(0.006)$ & $(0.006)$ & $(0.006)$ \\
\hline \multirow[t]{2}{*}{ Education } & -0.00 & -0.00 & -0.00 & -0.00 & -0.00 \\
\hline & $(0.004)$ & $(0.004)$ & $(0.004)$ & $(0.004)$ & $(0.004)$ \\
\hline \multirow[t]{2}{*}{ Female } & $0.00^{\star *}$ & $0.00^{\star *}$ & $0.00^{\star \star}$ & $0.00^{* *}$ & $0.00^{\star *}$ \\
\hline & $(0.000)$ & $(0.000)$ & $(0.000)$ & $(0.000)$ & $(0.000)$ \\
\hline \multirow[t]{2}{*}{ Household income } & $-0.08^{\star}$ & $-0.08^{\star}$ & $-0.08^{\star}$ & $-0.08^{\star}$ & $-0.08^{\star}$ \\
\hline & $(0.042)$ & $(0.041)$ & $(0.041)$ & $(0.042)$ & $(0.041)$ \\
\hline \multirow[t]{2}{*}{ Party identification } & $-0.14^{\star \star \star}$ & $-0.14^{\star \star \star}$ & $-0.14^{\star \star \star}$ & $-0.14^{\star \star *}$ & $-0.14^{\star \star \star}$ \\
\hline & $(0.043)$ & $(0.043)$ & $(0.043)$ & $(0.043)$ & $(0.043)$ \\
\hline \multirow[t]{2}{*}{ Age } & $-0.06^{\star \star \star}$ & $-0.06^{\star \star \star}$ & $-0.06^{\star \star \star}$ & $-0.06^{\star \star \star}$ & $-0.06^{\star \star \star}$ \\
\hline & $(0.013)$ & $(0.013)$ & $(0.013)$ & $(0.013)$ & $(0.013)$ \\
\hline \multirow[t]{2}{*}{ Age squared } & $-0.13^{\star \star \star}$ & $-0.13^{\star \star \star}$ & $-0.12^{\star \star \star}$ & $-0.13^{\star \star \star}$ & $-0.12^{\star \star \star}$ \\
\hline & $(0.042)$ & $(0.042)$ & $(0.042)$ & $(0.042)$ & $(0.042)$ \\
\hline \multirow[t]{2}{*}{ Black } & $-0.08^{\star \star}$ & $-0.07^{\star \star}$ & $-0.07^{\star \star}$ & $-0.08^{\star \star}$ & $-0.07^{\star \star}$ \\
\hline & $(0.035)$ & $(0.035)$ & $(0.035)$ & $(0.035)$ & $(0.035)$ \\
\hline \multirow[t]{2}{*}{ Hispanic } & $-0.10^{\star \star}$ & $-0.10^{\star \star}$ & $-0.10^{\star \star}$ & $-0.10^{\star \star}$ & $-0.10^{\star \star}$ \\
\hline & $(0.043)$ & $(0.043)$ & $(0.043)$ & $(0.043)$ & $(0.043)$ \\
\hline \multirow[t]{2}{*}{ Balance bill protections } & 0.02 & 0.02 & 0.02 & 0.02 & 0.02 \\
\hline & $(0.015)$ & $(0.015)$ & $(0.015)$ & $(0.015)$ & $(0.015)$ \\
\hline
\end{tabular}


Table A7. (Continued.)

\begin{tabular}{lccccc}
\hline Variables & $(1)$ & $(2)$ & $(3)$ & $(4)$ & $(5)$ \\
Self & Family & Both & Any & Size \\
\hline Constant & $1.02^{\star \star \star}$ & $1.01^{\star \star *}$ & $1.01^{\star \star \star}$ & $1.01^{\star \star *}$ & $1.01^{\star \star \star}$ \\
& $(0.134)$ & $(0.134)$ & $(0.134)$ & $(0.134)$ & $(0.133)$ \\
\hline Observations & 4429 & 4445 & 4445 & 4429 & 4445 \\
\hline
\end{tabular}

Note: Robust standard errors in parentheses.

${ }^{* * *} p<0.01,{ }^{* *} p<0.05,{ }^{*} p<0.10$.

Cite this article: Callaghan T, Haeder SF, Sylvester S (2022). Past experiences with surprise medical bills drive issue knowledge, concern and attitudes toward federal policy intervention. Health Economics, Policy and Law 17, 298-331. https:// doi.org/10.1017/S1744133121000281 